\title{
U.S. Geological Survey Noble Gas Laboratory's Standard Operating Procedures for the Measurement of Dissolved Gas in Water Samples
}

Chapter 11 of

Section A, Water Analysis

Book 5, Laboratory Analysis

Techniques and Methods 5-A11

U.S. Department of the Interior

U.S. Geological Survey 
Front cover: Photograph of Firehole River, Yellowstone National Park.

Back cover: Top, Photograph of the author outside the Exell Helium Plant, southern Moore County, Texas. Bottom, Photographs of the U.S. Geological Survey Noble Gas Laboratory, purification line number two.

Photographs by Andrew Hunt, U.S. Geological Survey. 


\section{U.S. Geological Survey Noble Gas \\ Laboratory's Standard Operating \\ Procedures for the Measurement of Dissolved Gas in Water Samples}

By Andrew G. Hunt

Chapter 11 of

Section A, Water Analysis

Book 5, Laboratory Analysis

Techniques and Methods 5-A11 


\title{
U.S. Department of the Interior SALLY JEWELL, Secretary
}

\section{U.S. Geological Survey Suzette M. Kimball, Acting Director}

\author{
U.S. Geological Survey, Reston, Virginia: 2015
}

For more information on the USGS — the Federal source for science about the Earth, its natural and living resources, natural hazards, and the environment—visit http://www.usgs.gov or call 1-888-ASK-USGS.

For an overview of USGS information products, including maps, imagery, and publications, visit http://www.usgs.gov/pubprod/.

Any use of trade, firm, or product names is for descriptive purposes only and does not imply endorsement by the U.S. Government.

Although this information product, for the most part, is in the public domain, it also may contain copyrighted materials as noted in the text. Permission to reproduce copyrighted items must be secured from the copyright owner.

Suggested citation:

Hunt, A.G., 2015, Noble Gas Laboratory's standard operating procedures for the measurement of dissolved gas in water samples: U.S. Geological Survey Techniques and Methods, book 5, chap. A11, 22 p., http://dx.doi.org/10.3133/ tm5A11.

ISSN 2328-7055 (online) 


\section{Contents}

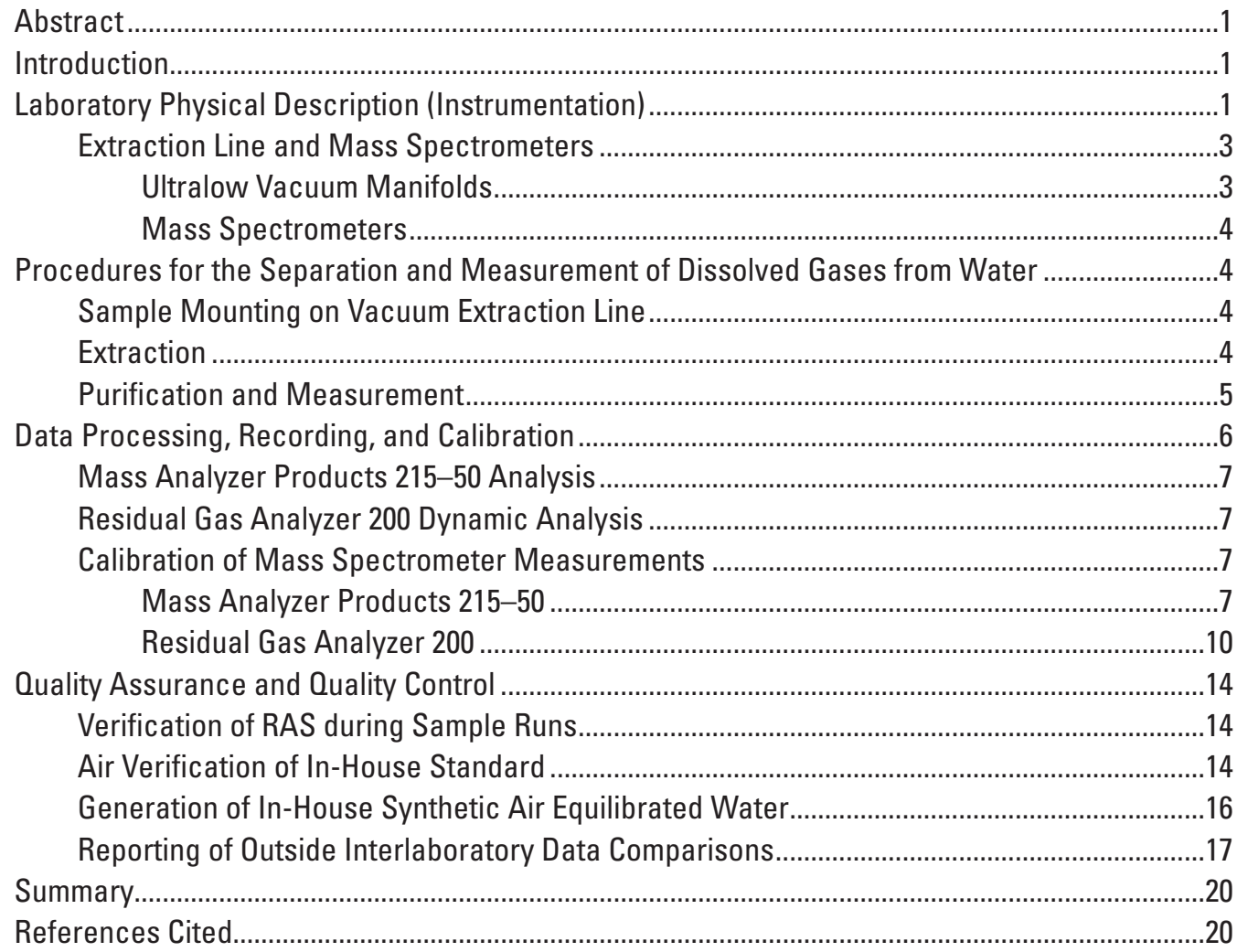

\section{Figures}

1. Conceptual representation of the ultralow vacuum system for the measurement of dissolved gas samples ..................................................................................................

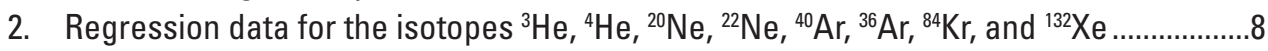

3. Results for the gas calibration of the Residual Gas Analyzer ............................................

4. Calibration curves of Riverside Air Standard concentration to MAP 215-50 machine response.

5. Conceptual representation of the equilibration apparatus for creating air equilibrated water 16

6. Plots of total dissolved gas pressure, dissolved oxygen, and temperature against time for three separate air equilibrated water experiments

\section{Tables}

1. Instrument precision for $\mathrm{He}, \mathrm{Ne}, \mathrm{Ar}, \mathrm{Kr}$, and $\mathrm{Xe}$

2. Calculation method for nitrogen, oxygen, and argon from the quadrupole mass spectrometer data

3. Summary of air verification of in-house standard.........................................................15

4. Air equilibrated water summary................................................................................... 19 


\section{Conversion Factors}

Inch/Pound to SI

\begin{tabular}{lcl}
\hline \multicolumn{1}{c}{ Multiply } & By & \multicolumn{1}{c}{ To obtain } \\
\hline inch (in.) & Length & \\
inch (in.) & 2.54 & centimeter (cm) \\
\hline & 25.4 & millimeter (mm) \\
\hline ounce, fluid (fl. oz) & Volume & \\
pint (pt) & 0.02957 & liter (L) \\
quart (qt) & 0.4732 & liter (L) \\
gallon (gal) & 0.9464 & liter (L) \\
\hline & 3.785 & liter (L) \\
\hline gallon per minute (gal/min) & Flow rate \\
\hline & 0.06309 & liter per second (L/s) \\
\hline ounce, avoirdupois (oz) & Mass & \\
pound, avoirdupois (lb) & 28.35 & kram (g) \\
& 0.4536 & kilogram (kg) \\
\hline atmosphere, standard (atm) & Pressure & kilopascal $(\mathrm{kPa})$ \\
bar & 101.3 & kilopascal $(\mathrm{kPa})$ \\
inch of mercury at $\left.60^{\circ} \mathrm{F} \mathrm{(in} \mathrm{Hg}\right)$ & 100 & kilopascal $(\mathrm{kPa})$ \\
\hline
\end{tabular}

SI to Inch/Pound

\begin{tabular}{lll}
\hline \multicolumn{1}{c}{ Multiply } & By & \multicolumn{1}{c}{ To obtain } \\
\hline & Length & \\
\hline centimeter $(\mathrm{cm})$ & 0.3937 & inch (in.) \\
millimeter $(\mathrm{mm})$ & 0.03937 & inch (in.) \\
\hline \multicolumn{1}{l}{ Volume } & \\
liter $(\mathrm{L})$ & 33.82 & ounce, fluid (fl. oz) \\
liter $(\mathrm{L})$ & 2.113 & pint $(\mathrm{pt})$ \\
liter $(\mathrm{L})$ & 1.057 & quart (qt) \\
cubic centimeter $\left(\mathrm{cm}^{3}\right)$ & 0.2642 & gallon (gal) \\
liter $(\mathrm{L})$ & 0.06102 & cubic inch $\left(\mathrm{in}^{3}\right)$ \\
\hline & 61.02 & cubic inch (in $\left.{ }^{3}\right)$ \\
\hline liter per second $(\mathrm{L} / \mathrm{s})$ & Flow rate & \\
\hline & 15.85 & gallon per minute $(\mathrm{gal} / \mathrm{min})$ \\
\hline gram $(\mathrm{g})$ & Mass & \\
kilogram $(\mathrm{kg})$ & 0.03527 & ounce, avoirdupois $(\mathrm{oz})$ \\
& 2.205 & pound avoirdupois $(\mathrm{lb})$ \\
\hline kilopascal $(\mathrm{kPa})$ & Pressure & \\
kilopascal $(\mathrm{kPa})$ & 0.009869 & atmosphere, standard $(\mathrm{atm})$ \\
kilopascal $(\mathrm{kPa})$ & 0.01 & bar \\
\hline
\end{tabular}

Temperature in degrees Celsius $\left({ }^{\circ} \mathrm{C}\right)$ may be converted to degrees Fahrenheit $\left({ }^{\circ} \mathrm{F}\right)$ as follows:

$$
{ }^{\circ} \mathrm{F}=\left(1.8 \times{ }^{\circ} \mathrm{C}\right)+32
$$

Temperature in degrees Fahrenheit $\left({ }^{\circ} \mathrm{F}\right)$ may be converted to degrees Celsius $\left({ }^{\circ} \mathrm{C}\right)$ as follows:

$$
{ }^{\circ} \mathrm{C}=\left({ }^{\circ} \mathrm{F}-32\right) / 1.8
$$

Temperature in degrees Celsius $\left({ }^{\circ} \mathrm{C}\right)$ may be converted to degrees Kelvin $\left({ }^{\circ} \mathrm{K}\right)$ as follows:

$$
{ }^{\circ} \mathrm{K}={ }^{\circ} \mathrm{C}-273.15
$$

Temperature in degrees Kelvin $\left({ }^{\circ} \mathrm{K}\right)$ may be converted to degrees Celsius $\left({ }^{\circ} \mathrm{C}\right)$ as follows:

$$
{ }^{\circ} \mathrm{C}={ }^{\circ} \mathrm{K}+273.15
$$

Molar volume is defined at 1 atmosphere pressure and $0^{\circ} \mathrm{C}$ as: 1 mole $=22.414$ liters 


\section{Abbreviations}

\begin{tabular}{|c|c|}
\hline AEW & air equilibrated water \\
\hline $\operatorname{Ar}$ & argon \\
\hline${ }^{36} \mathrm{Ar}$ & argon-36 \\
\hline${ }^{38} \mathrm{Ar}$ & argon-38 \\
\hline${ }^{40} \mathrm{Ar}$ & argon-40 \\
\hline $\mathrm{cm}^{3}$ & cubic centimeter \\
\hline $\mathrm{cm}^{3} / \mathrm{cm}^{3}$ & cubic centimeter per cubic centimeter \\
\hline $\mathrm{cm}^{3} \mathrm{STP}$ & cubic centimeter at standard temperature and pressure \\
\hline $\mathrm{cm}^{3} \mathrm{STP} / \mathrm{g}_{\mathrm{H} 20}$ & cubic centimeter at standard temperature and pressure per gram of water \\
\hline CDEM & continuous dynode electron multiplier \\
\hline CEM & channel electron multiplier \\
\hline CFC & chlorofluorocarbons \\
\hline cps & counts per second \\
\hline $\mathrm{CH}_{4}$ & methane \\
\hline $\mathrm{CO}_{2}$ & carbon dioxide \\
\hline DO & dissolved oxygen \\
\hline $\mathrm{H}_{2}$ & hydrogen \\
\hline${ }^{3} \mathrm{H}$ & tritium \\
\hline $\mathrm{HCO}_{3}$ & bicarbonate \\
\hline $\mathrm{H}_{2} \mathrm{CO}_{3}$ & carbonic acid \\
\hline $\mathrm{He}$ & helium \\
\hline${ }^{3} \mathrm{He}$ & helium-3 \\
\hline${ }^{4} \mathrm{He}$ & helium-4 \\
\hline $\mathrm{H}_{2} \mathrm{O}$ & water vapor \\
\hline ICP-MS & inductively coupled plasma mass spectrometry \\
\hline $\mathrm{Kr}$ & krypton \\
\hline${ }^{84} \mathrm{Kr}$ & krypton-84 \\
\hline${ }^{86} \mathrm{Kr}$ & krypton-86 \\
\hline $\mathrm{LN}_{2}$ & liquid nitrogen \\
\hline MAP & mass analyzer products \\
\hline $\mathrm{mL}$ & milliliter \\
\hline $\mathrm{N}_{2}$ & nitrogen \\
\hline $\mathrm{Ne}$ & neon \\
\hline
\end{tabular}




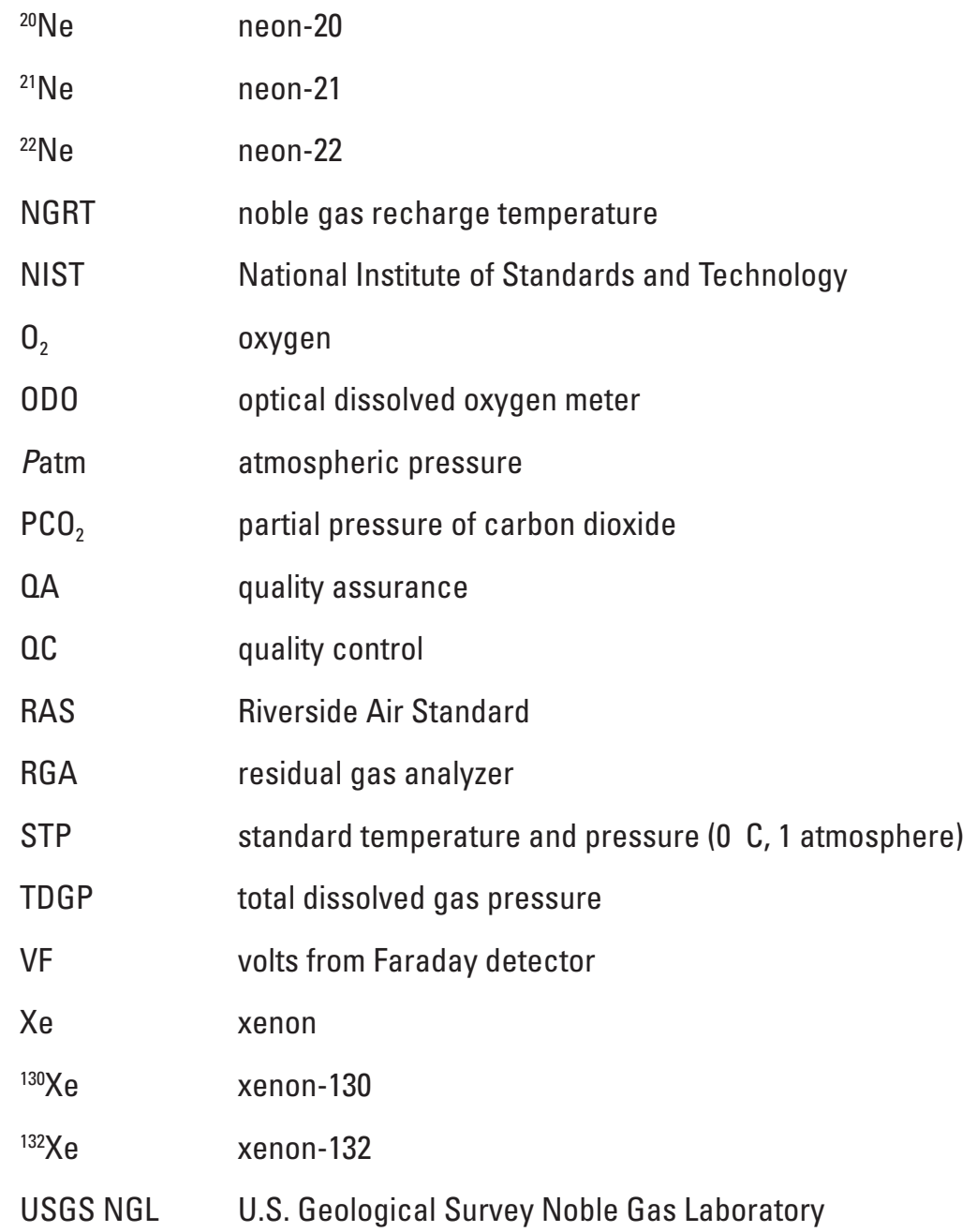

\section{Symbols}

$\begin{array}{ll}> & \text { greater than } \\ < & \text { less than } \\ >> & \text { much greater than } \\ \Leftrightarrow & \text { equivalent } \\ \approx & \text { approximately (nearly) equal to } \\ { }^{\circ} & \text { degree } \\ { }^{\circ} \mathrm{C} & \text { degrees Celsius } \\ { }^{\circ} \mathrm{K} & \text { degree Kelvin } \\ { }^{\circ} \% & \text { percent } \\ \pm & \text { plus or minus }\end{array}$




\title{
USGS Noble Gas Laboratory's Standard Operating Procedures for the Measurement of Dissolved Gas in Water Samples
}

\author{
By Andrew G. Hunt
}

\begin{abstract}
This report addresses the standard operating procedures used by the U.S. Geological Survey's Noble Gas Laboratory in Denver, Colorado, U.S.A., for the measurement of dissolved gases (methane, nitrogen, oxygen, and carbon dioxide) and noble gas isotopes (helium-3, helium-4, neon-20, neon-21, neon-22, argon-36, argon-38, argon-40, kryton-84, krypton-86, xenon-103, and xenon-132) dissolved in water. A synopsis of the instrumentation used, procedures followed, calibration practices, standards used, and a quality assurance and quality control program is presented. The report outlines the day-today operation of the Residual Gas Analyzer Model 200, Mass Analyzer Products Model 215-50, and ultralow vacuum extraction line along with the sample handling procedures, noble gas extraction and purification, instrument measurement procedures, instrumental data acquisition, and calculations for the conversion of raw data from the mass spectrometer into noble gas concentrations per unit mass of water analyzed. Techniques for the preparation of artificial dissolved gas standards are detailed and coupled to a quality assurance and quality control program to present the accuracy of the procedures used in the laboratory.
\end{abstract}

\section{Introduction}

The U.S. Geological Survey Noble Gas Laboratory (USGS NGL) has been refining procedures for the measurement of noble gas isotopes dissolved in water since the purchase of the first noble gas mass spectrometer by the laboratory in 1998 . Procedures for the measurement of noble gas compositions have been almost commonplace since the early to mid-1990s with such publications as Bayer and others (1989) outlining the procedures for extraction and measurement of helium-3 $\left({ }^{3} \mathrm{He}\right)$ and tritium $\left({ }^{3} \mathrm{H}\right)$ for use with ${ }^{3} \mathrm{H}-{ }^{3} \mathrm{He}$ groundwater dating. The recognition of amounts of excess gas associated with groundwater and oceanic water samples (for example, excess air by Heaton and Vogel, 1981) pushed for the measurement of other noble gases (neon, argon, krypton, and xenon) to derive variable parameters to better understand the effects of recharge processes on noble gas concentrations in recharge (for example,
Stute and Sonntag, 1992; Aeschbach-Hertig and others, 1999, 2000; Ballentine and Hall, 1999). These recharge models also produced information such as recharge temperatures (noble gas recharge temperature [NGRT]), amounts of excess air both fractionated and unfractionated, concentrations of excess helium-4 $\left({ }^{4} \mathrm{He}\right)$, and amounts of tritogenically derived ${ }^{3} \mathrm{He}\left({ }^{3} \mathrm{He} *\right)$ used in ${ }^{3} \mathrm{H} /{ }^{3} \mathrm{He}$ groundwater dating (Schlosser, 1992). The push to derive more information from an individual sample has led to advances in instrumentation and procedures that increased the sensitivity to various noble gas components from progressively smaller sample volumes. The USGS NGL has designed unique procedures and instrumentation that are based on previously documented procedures (Poreda and others, 1988; Bayer and others, 1989; Solomon and others, 1992, 1996; Beyerle and others, 2000; Kulongoski and Hilton, 2002) but with distinct and unique differences that derive the working procedure for the extraction and measurement of ${ }^{3} \mathrm{He},{ }^{4} \mathrm{He}$, neon- $20\left({ }^{20} \mathrm{Ne}\right)$, neon-22 $\left({ }^{22} \mathrm{Ne}\right)$, argon-36 $\left({ }^{36} \mathrm{Ar}\right)$, argon-40 $\left({ }^{40} \mathrm{Ar}\right)$, krypton-84 $\left({ }^{84} \mathrm{Kr}\right)$, krypton-86 $\left({ }^{86} \mathrm{Kr}\right)$, xenon-130 $\left({ }^{130} \mathrm{Xe}\right)$, and xenon-132 $\left({ }^{132} \mathrm{Xe}\right)$ as well as major gas components of hydrogen $\left(\mathrm{H}_{2}\right)$, water vapor $\left(\mathrm{H}_{2} \mathrm{O}\right)$, methane $\left(\mathrm{CH}_{4}\right)$, nitrogen $\left(\mathrm{N}_{2}\right)$, oxygen $\left(\mathrm{O}_{2}\right)$, argon (Ar), and carbon dioxide $\left(\mathrm{CO}_{2}\right)$ from relatively small water samples. These procedures have been used in previous studies (Nordstrom and others, 2005; Naus and others, 2005; Christenson and others, 2009; Hunt and others, 2010; Katz and others, 2009; Lambert and others, 2009; McMahon and others, 2013, 2015; Plummer and others, 2012, 2013; Sanford and others, 2013) and are presented here in their entirety.

\section{Laboratory Physical Description (Instrumentation)}

The apparatus designed by the USGS NGL for the measurement of dissolved gases in water samples comprises three separate sections (extraction, process, and inlet manifolds) that together make up the complete vacuum extraction line (fig. 1). The base component is an ultralow vacuum extraction line which is connected to a gas-source, magnetic sector mass spectrometer (Mass Analyzer Products Model 215-50 [MAP 215-50]) and a quadrupole mass spectrometer (Stanford 


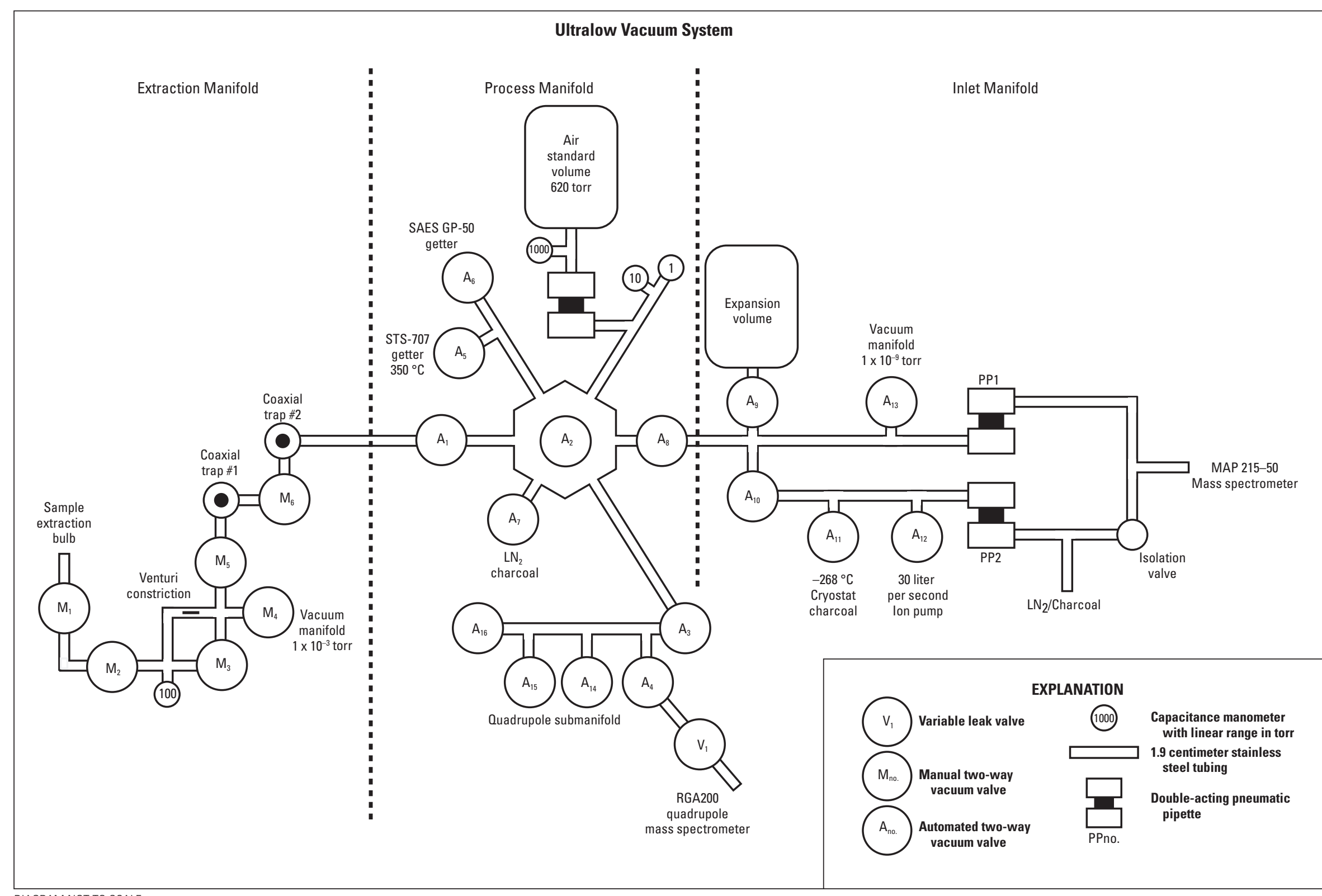

DIAGRAM NOT TO SCALE

Figure 1. Conceptual representation of the ultralow vacuum system for the measurement of dissolved gas samples. Vacuum line is managed as three separate parts: the extraction manifold, the process manifold, and the inlet manifold. ${ }^{\circ} \mathrm{C}$, degrees Celsius; LN 2 liquid nitrogen; MAP 215-50, Mass Analyzer Products Model 215-50; RGA200, Stanford Research Systems Residual Gas Analyzer; SAES GP-50 and STS-707, nonevaporable getters. 
Research Systems Residual Gas Analyzer [RGA200]). The apparatus is controlled through a personal computer operating in-house software developed using National Instrument's LabVIEW system design software. The software can be run in a semiautomated operation mode for the duplication of repetitive procedures or can be manually manipulated by computer control for specialty operations. The ultralow vacuum system is designed to accept any gas sample into the extraction manifold, remove gas fractions that interfere (for example, $\mathrm{CH}_{4}$, $\mathrm{N}_{2}, \mathrm{O}_{2}$, other hydrocarbons and active gases) with the measurement of the noble gas isotopes in the MAP 215-50, and separate the noble gas fractions for accurate analysis of noble gas isotopic compositions in the MAP 215-50 and RGA200.

\section{Extraction Line and Mass Spectrometers}

\section{Ultralow Vacuum Manifolds}

The unique design of the vacuum manifold is different than typical noble gas research lines in that the design uses large-volume manifolds $(1.9$ centimeters $[\mathrm{cm}][0.75 \mathrm{inch}]$ for the sample side of the system) which allow for high conductance of gases in the vacuum manifold coupled with high compression rate, turbomolecular pumping systems attached to the manifold stem. The increased conductance advantage ensures that there is little cross contamination of gases from previous samples in the system and a short timeframe to take a sample from atmospheric pressure down to ultralow vacuum manifold for sample gas extraction and analysis. In general, the system is constructed from stainless steel tubing with all-metal valves equipped with conflate-type flanges utilizing copper gaskets. The entire vacuum line is broken down into three separate sections: extraction manifold, process manifold, and inlet manifold. The concept of the three-manifold system is to be able to load a contained gas or fluid sample onto the manifold at atmospheric pressure, pump down the sample container to manifold pressure, extract the dissolved gases from the sample media (for example, water), remove all active gas components, and extract and separate noble gas components for measurement in the system's mass spectrometers.

The extraction manifold (fig. 1) is designed to accept a variety of sample containers at valve $\mathrm{M}_{1}$, pump down the connection to an initial pressure of $1 \times 10^{-3}$ torr through a rotary vane vacuum pump (valve $\mathrm{M}_{4}$ ), then close off the valve $\mathrm{M}_{4}$ and open the sample to the process manifold where it can be further pumped down to $1 \times 10^{-9}$ torr, at which point the sample is at sufficient pressure to ensure little-to-no contamination for the introduction of the sample to the process manifold. The extraction manifold is equipped with a 100-torr capacitance manometer for measurement on processing pressures during sample introduction, a fixed-Venturi constriction for use in water extraction of dissolved gas (see Procedures for the Separation and Measurement of Dissolved Gases from Water section), and two coaxial finger traps for gas condensation (for example, water vapor or carbon dioxide depending on temperature) from the sample stream. The valves $M_{1}$ through $M_{6}$ are manually operated and are purposed specifically for user-operated extractions within the manifold. The extraction manifold is connected to the process line by automated valve $A_{1}$.

The process manifold is designed to accept gas from the extraction manifold, measure total gas compositions with an attached quadrupole mass spectrometer, and remove any active gases to purify the noble gas fraction of the extracted sample in preparation of noble gas compositional analysis. Coupled with the processing system is an in-house air standard dispensed through a 0.1808 cubic centimeter, double-acting pneumatic pipette, and three capacitance manometers, two (1 torr and 10 torr range) for measurement of sample pressures in the manifold, and one (1,000 torr) for measurement of the standard pressure. The manifold is pumped through valve $\mathrm{A}_{2}$ by a turbomolecular pump $\left(\mathrm{N}_{2}\right.$ pumping speed of 260 liters per second, compression ratio for $\mathrm{N}_{2}$ of $>1 \times 10^{11}$ ). The purification element of the manifold is derived from three separate traps on the manifold. Two of the traps are loaded with materials that sorb active gases such as $\mathrm{O}_{2}, \mathrm{H}_{2} \mathrm{O}, \mathrm{CO}_{2}, \mathrm{~N}_{2}$, and $\mathrm{CH}_{4}$ by a chemical reaction under vacuum. The manufacturer refers to these materials as nonevaporable getters in which a proprietary material coating mounted on pills or strips is actively heated to promote the chemical sorption process in the trap. One trap $\left(\mathrm{A}_{5}\right)$ contains STS-707 pills heated to $350{ }^{\circ} \mathrm{C}$ with an external resistive heater, and another trap $\left(\mathrm{A}_{6}\right)$ has a cartridge element that is heated with an internal nichrome heating element (SAES GP-50). The third trap $\left(\mathrm{A}_{7}\right)$ on the manifold contains activated charcoal cooled by liquid nitrogen $\left(\mathrm{LN}_{2}\right)$ which is generally used to sorb and release any gases that cannot be processed by the two getters and also promote cryogenic separation of heavy noble gases (Ar, $\mathrm{Kr}$, and $\mathrm{Xe})$ from light noble gases ( $\mathrm{He}$ and $\mathrm{Ne}$ ).

A separate submanifold for the RGA200 is attached by valve A3 to the process manifold. The RGA200 is contained in a separate vacuum manifold pumped by another turbomolecular pump system which is connected to the submanifold by an automated valve $\left(\mathrm{A}_{4}\right)$ and a manually actuated variable leak valve $\left(\mathrm{V}_{1}\right)$. The RGA can be completely isolated from the vacuum manifold by an inline gate valve (not shown). This submanifold contains another externally heated STS-707 getter and chilled activated charcoal traps $\left(\mathrm{A}_{15}, \mathrm{~A}_{16}\right)$. The configuration allows for aliquots of sample gas to be exposed to the RGA200 from the process manifold and also acts as a separate process manifold for the RGA200.

The third section of the vacuum line is the inlet manifold which is the cleanest part of the vacuum line. This section of the line accepts purified noble gases from the process manifold, introduces aliquots of gas into the MAP 215-50 for direct measurement of noble gases, or processes the noble gases further to cryogenically separate $\mathrm{He}$ from $\mathrm{Ne}$ gas fractions. Key features for this manifold are two double-acting pneumatic pipettes $\left(\mathrm{PP}_{1}\right.$ and $\left.\mathrm{PP}_{2}\right)$ for the metering of samples to the MAP 215-50 and an activated charcoal trap $\left(\mathrm{A}_{11}\right)$ mounted on top of a cryostat head which is maintained at $-268^{\circ} \mathrm{C}$. This cryogenic trap is mainly used to sorb and separate $\mathrm{He}$ from $\mathrm{Ne}$ for isotopic measurement on the MAP 215-50. An additional expansion volume (at $\mathrm{A}_{9}$ ) is attached in order to reduce gas concentrations in the manifold, increasing the measurement 
range of gases of the MAP 215-50. Pressure in the manifold is typically $1 \times 10^{-9}$ torr, pumped by an ion pump (30 liters per second, negative triode) $\left(\mathrm{A}_{12}\right)$, but also has the option of being pump by the same turbomolecular pump manifold that is attached to the RGA200.

\section{Mass Spectrometers}

The MAP 215-50 is equipped with an inline Faraday detector mounted on the high mass side of the optic axis and an off-axis channeltron multiplier run in digital pulse counting mode. The Faraday detector has a linear response range from 0 to 11 volts (V) as measured on a digital voltmeter; whereas the multiplier has a linear range of detections between 0 and 2 million counts per second (cps). The filament used is a 4-coil tungsten filament used for electron emission in a Nier-type source (Wallington, 1971) run with a trap current of 400 microamperes with a resolution greater than 600 (typically 620). The MAP 215-50 is operated in both manual (computer assisted) mode, where software is controlled by an operator in order to acquire data and in automation mode, where LabVIEW programing software (user developed) controls aspects of data gathering.

The RGA200 is positioned on a submanifold separate from the process manifold of the vacuum line. Gas is introduced to the RGA through a variable leak valve $\left(\mathrm{V}_{1}\right.$, fig. 1) and can be run in dynamic mode (gas is swept through the RGA at a set pressure and pumped away) or static mode (gas is introduced to the RGA in a closed volume) by closing off the RGA from the pumping manifold. The quadrupole mass spectrometer is equipped with a Faraday cup detector and a continuous dynode electron multiplier (CDEM) run in analogue operating mode. The filament is a dual thoriated-iridium used for electron emission. Similar to the MAP 215-50, the RGA200 is operated manually by an operator using factory supplied software and operated autonomously by LabVIEW software drivers supplied by the manufacturer.

\section{Procedures for the Separation and Measurement of Dissolved Gases from Water}

After a sample arrives at the USGS NGL, a visual inspection of the copper tube containing the sample is assessed by trained laboratory personnel. The copper tube is cleaned with 200-proof ethanol, affixed with a $37^{\circ}$ flare fitting (nut and compression sleeve), weighed for derivation of total sample mass contained in the sample tube, and recorded in a laboratory notebook with project name, sample identification number, date sample was collected, and time the sample was extracted and analyzed. This notebook is cross referenced by date to the instrument notebooks in the laboratory for internal use and data storage.

\section{Sample Mounting on Vacuum Extraction Line}

Procedures for the measurement of the dissolved gases in water begin with the mounting of the sample tube onto the extraction manifold and pumping down the manifold to ultralow vacuum. The clamped, copper sample tube is fitted with a $37^{\circ}$ flare-type compression fitting and affixed to the top of the manifold's extraction flask mounted at valve $\mathrm{M}_{1}$, which is immersed in an ultrasonic bath maintained at $32{ }^{\circ} \mathrm{C}$. Valves $\mathrm{M}_{1}, \mathrm{M}_{2}, \mathrm{M}_{3}, \mathrm{M}_{5}$, and $\mathrm{M}_{6}$ are opened and pumped down to rough vacuum pressures through valve $\mathrm{M}_{4}$. Valve $\mathrm{A}_{1}$ is closed at this stage. The extraction bulb is gently heated with a heat gun to approximately $50^{\circ} \mathrm{C}$, allowing the extraction manifold with sample mounted to reach a lower pressure of approximately $1 \times 10^{-3}$ torr (limit of the rotary vacuum pump). Two Dewar vacuum flasks are positioned around the two coaxial traps. On trap 1, a Dewar flask of liquid nitrogen gas $\left(\mathrm{LN}_{2}\right)$ chills the finger to $-196{ }^{\circ} \mathrm{C}$ whereas on trap 2 a Dewar flask of ethanol and (or) dry ice slush chills the trap to $-75^{\circ} \mathrm{C}$. Valve $\mathrm{M}_{4}$ is closed and Valve $\mathrm{A}_{1}$ is opened, pumping the extraction manifold down to ultralow vacuum through $\mathrm{A}_{2}$. Valves $\mathrm{A}_{5}$, $\mathrm{A}_{6}, \mathrm{~A}_{7}$ (getters and charcoal finger), $\mathrm{A}_{8}$, and $\mathrm{A}_{4}$ (transmission valves) are closed. The extraction manifold is pumped down below $1 \times 10^{-7}$ torr (typically $<2 \times 10^{-8}$ torr) to the point the sample is ready for extraction.

\section{Extraction}

Valves $A_{1}, M_{6}, M_{3}$, and $M_{1}$ are closed, and the sample clamp is removed from the copper sample tube, and the sample tube is rerounded. The sample is moved from the sample tube to the extraction manifold by gravity and pressure. The sample tube and top of the extraction bulb are gently heated to $50{ }^{\circ} \mathrm{C}$ to ensure that all of the sample water has passed into the extraction bulb. Valve $\mathrm{M}_{1}$ is then opened, and the ultrasonic bath is agitated for 13 minutes. Water vapor and gas are forced through the Venturi constriction where the water condenses in the $\mathrm{LN}_{2}$ cooled coaxial trap (trap 1). The rapid movement of water vapor through the Venturi constriction traps the extracted gas on the trap side of the constriction. This extraction method is commonly referred to as water pumping of the gas through the constriction. Initially, both gas and water vapor pass through the Venturi constriction with the water vapor freezing out into trap $1\left(\mathrm{LN}_{2}\right)$ and the gas being trapped on the trap-side of the constriction by the force of the water vapor passing through the constriction from the extraction flask side. Pressure of the extraction is monitored by the 100-torr capacitance manometer, typically around 26 torr or the vapor pressure of water in the manifold. After 15 minutes, valve $\mathrm{M}_{2}$ is closed, and valve $\mathrm{M}_{3}$ is opened to allow any condensed water vapor to migrate to trap 1; pressure in the manifold drops to less than 1 torr in approximately 3 minutes. After freezing down the extracted gases and water vapor trapped between valves $\mathrm{M}_{2}, \mathrm{M}_{4}$ and $\mathrm{M}_{6}$, the $\mathrm{LN}_{2}$ Dewar flask is removed and replaced with a Dewar flask of warm 
$\left(\approx 50-60^{\circ} \mathrm{C}\right.$ ) water. The water bath warms the finger and defrosts the water ice and any trapped gas in trap 1; pressure consequently rises back to 26 torr (water vapor pressure). The Dewar flask of warm water is then removed, and a Dewar flask of ethanol and (or) dry ice slush is applied to gradually refreeze the trap, freezing out the water vapor and (or) fluid and separating gas into the headspace. Measured pressures at this point vary depending on the sample size and compositions; for normal, air-saturated water samples, the pressure drops to approximately 2 torr. Valve $\mathrm{M}_{6}$ is then opened to expand the extracted sample gas into trap 2 (also ethanol and [or] dry-ice slush) to complete the sample extraction.

\section{Purification and Measurement}

Post sample extraction, the processing of the dry gas is fully automated for valve sequencing and data acquisition from the pressure gages and mass spectrometers attached to the line. A relatively simple LabVIEW procedure is initiated post sample extraction by the operator. It initializes the valve statue (Open $\mathrm{A}_{2}, \mathrm{~A}_{3}, \mathrm{~A}_{9}, \mathrm{~A}_{10}$, and $\mathrm{A}_{12}$. Closed $\mathrm{A}_{1}, \mathrm{~A}_{4}, \mathrm{~A}_{5}, \mathrm{~A} 6, \mathrm{~A}_{7}$, $\mathrm{A}_{8}, \mathrm{~A}_{11}, \mathrm{~A}_{13}, \mathrm{~A}_{14}, \mathrm{~A}_{15}, \mathrm{~A}_{16}$, and all pipettes), isolates the process manifold from vacuum manifolds (closes $\mathrm{A}_{2}$ ), and introduces the sample gas into the manifold (opens $A_{1}$ ). Sample gas is allowed to expand into the manifold and equilibrate to the expansion volume and temperature ( 2 minutes). Pressure in the line is then measured by both 1 -torr and 10-torr capacitance manometer heads (total linear range of measurement 0.0005 to 10.000 torr).

Prior to purification of the noble gas components, an aliquot of gas is introduced to the RGA200 for a dynamic analysis of the bulk composition of gas. All sample data are derived from the RGA200 as raw amperage output of the CDEM, run at optimum focal parameters of the RGA200. Initially, a baseline measurement on the RGA200 is performed for $\mathrm{H}_{2}, \mathrm{He}, \mathrm{CH}_{4}, \mathrm{H}_{2} \mathrm{O}, \mathrm{N}_{2}, \mathrm{O}_{2}, \mathrm{Ar}$, and $\mathrm{CO}_{2}$ using manufacturersupplied LabVIEW programming. The initial pressure on the manifold is $1 \times 10^{-9}$ torr. Valve $\mathrm{A}_{4}$ is then opened, and sample gas is regulated to stream sample gas into the quadrupole at a pressure of $2 \times 10^{-7}$ torr through the variable leak valve $\mathrm{V}_{1}$. The measurement of $\mathrm{H}_{2}, \mathrm{He}, \mathrm{CH}_{4}, \mathrm{H}_{2} \mathrm{O}, \mathrm{N}_{2}, \mathrm{O}_{2}, \mathrm{Ar}$, and $\mathrm{CO}_{2}$ is repeated, and the baseline is subtracted from the data to complete the dynamic run of the bulk gas sample. Valve $\mathrm{A}_{4}$ is then closed to complete the procedure.

After the dynamic run on the RGA200 has completed, valve $\mathrm{A}_{5}$ is opened and the STS-707 getter is exposed to the sample gas. The getter adsorbs the active gas components for a total time of 5 minutes, then valve $\mathrm{A}_{6}$ is opened for another 5 minutes, exposing the SAES GP-50 cartridge to purify the sample gas further. Depending on data gathered during the dynamic run, these times can be manually extended to allow the getters more time to adsorb difficult gases such as $\mathrm{CH}_{4}$, which take longer to adsorb at the set operating temperatures. After this process, the remaining sample gas is completely composed of noble gases for measurement on the
MAP 215-50. The typical composition of the noble gas fraction for standard, air-saturated water is $\mathrm{Ar}>>\mathrm{Ne}>\mathrm{Kr}>\mathrm{He}>\mathrm{Xe}$ (where $>>$ is much greater than); however, in water samples with extremely high amounts of excess He $\left(10^{-5}\right.$ to ${ }^{-4}$ cubic centimeters at standard temperature and pressure (temperature $0{ }^{\circ} \mathrm{C}$, pressure 1 atmosphere, (atm), or $22.414 \mathrm{l} / \mathrm{mole}$ for molar volume, McNaught and Wilkinson, 1997) per gram of water $\left[\mathrm{cm}^{3} \mathrm{STP} / \mathrm{g}\right]$ range), the composition is reflected by $\mathrm{He}>\mathrm{Ar}>>\mathrm{Ne}>\mathrm{Kr}>\mathrm{Xe}$. Typical pressures measured at this stage by the capacitance manometers are between 0.007 and 0.002 torr depending on gas composition.

Valve $A_{10}$ is closed and Valve $A_{8}$ is opened to advance the mixed noble gas sample to the MAP 215-50 pipette (PP1) with the expansion volume open on the inlet manifold $\left(\mathrm{A}_{9}\right)$, and the gas is allowed to equilibrate to the volume for 2 minutes. The pipette (PP1) is then used to extract three sequential volumes of approximately $0.2 \mathrm{~cm}^{3}$ for measurement of the $\mathrm{Xe}$, $\mathrm{Kr}$, and Ar gas fractions of the sample gas. Prior to exposing the sample gas to the MAP 215-50, a software procedure is executed to prepare the MAP 215-50 to measure the specific isotopic composition of a selected element. The MAP 215-50 is then isolated from the flight tube's 30 liter per second ion pump (not shown), and the extracted sample volume from the pipette is allowed to expand into the mass spectrometer. Software then follows an automated procedure for discrete measurement of the noble gas isotopes in the mixed gas composition. The procedure starts with a peak centering routine to find the peak flat for the isotopes followed by an iterative measurement of the isotopic peaks. Because of its high mass and low abundance, $\mathrm{Xe}$ is run first using the multiplier detector only to measure the isotopes of ${ }^{132} \mathrm{Xe}$ and ${ }^{130} \mathrm{Xe}$ and is then pumped away. The second aliquot measured is for $\mathrm{Kr}$ isotopes $\left({ }^{86} \mathrm{Kr}\right.$ and ${ }^{84} \mathrm{Kr}$ ) using the multiplier detector, then it is also pumped away. The third volume expanded into the mass spectrometer is measured for Ar isotopes $\left({ }^{40} \mathrm{Ar},{ }^{38} \mathrm{Ar}\right.$, and $\left.{ }^{36} \mathrm{Ar}\right)$ using the Faraday detector. After the completion of the Ar procedure, the mass spectrometer is pumped to base pressure by an ion pump. All data collection procedures prescan each isotope to calibrate the mass calibration of the magnet to the digital masses of the isotopes and then acquire the concentration data by use of a peak-jump routine. After the Ar measurement procedure has been initiated, valve $A_{7}$ is opened on the process manifold. The $\mathrm{LN}_{2}$ and (or) charcoal trap adsorbs the Ar, $\mathrm{Kr}$, and Xe components of the sample gases for 10 minutes, leaving behind only $\mathrm{He}$ and $\mathrm{Ne}$ components of the sample gas.

Next, valve $A_{12}$ is closed, and valves $A_{10}$ and $A_{11}$ are opened, exposing the remaining sample gas to the activated charcoal trap at $-268^{\circ} \mathrm{C}$. The trap sorbs all remaining gas into the charcoal in the trap for 10 minutes, completing the separation of the $\mathrm{He}$ and $\mathrm{Ne}$ components from $\mathrm{Ar}, \mathrm{Kr}$, and Xe parts. Valves $A_{11}, A_{1}$, and $A_{7}$ are closed, and valve $A_{2}$ is open to initiate the purging of the process and inlet manifolds. A manual preparation begins on the extraction manifold to clean out the vacuum lines of residual water from the previous sample extraction and mount the next sample. The $\mathrm{LN}_{2}$ Dewar flask on the charcoal trap on valve $A_{7}$ is removed, and the trap 
is allowed to warm to room temperature. The thermal control for the cryostat is increased to $-227^{\circ} \mathrm{C}$ and maintained at this temperature to promote separation of the $\mathrm{He}$ and $\mathrm{Ne}$ gas fractions for 10 minutes. Helium desorbs completely at $-227^{\circ} \mathrm{C}$, leaving over 99 percent of the $\mathrm{Ne}$ adsorbed to the charcoal in the trap. Valves $\mathrm{A}_{8}, \mathrm{~A}_{9}$, and $\mathrm{A}_{10}$ are closed, and valve $\mathrm{A}_{11}$ is open to the mass spectrometer's second pipette $\left(\mathrm{PP}_{2}\right)$. An aliquot of the He fraction is pipetted into the static mass spectrometer, and the ${ }^{4} \mathrm{He}$ peak is measured for intensity on the Faraday detector. The computer code written for the vacuum manifold and mass spectrometer is then used to calculate the required inlet fraction of the He to maintain linear limits of the Faraday detector $(0-11 \mathrm{~V})$. The software may inlet the entire He sample fraction or follows a set procedure to back expand the sample fraction into the expansion volume in the inlet manifold and reevaluate whether the sample size is in the linear range of the detector. This iterative process can be repeated multiple times allowing for large samples of $\mathrm{He}$ to be reduced in size for measurement of He isotopes in the linear ranges of the detectors while calculating the reduction in sensitivity by the number of iterations to determine total concentration. After the He has been isolated in the MAP 215-50 for isotopic composition measurement, valve $A_{11}$ is closed, and the remaining residual gas in the inlet manifold is pumped to the vacuum manifold by valve $A_{13}$ (valves $A_{9}$ and $A_{10}$ open). The He measurement procedure measures both ${ }^{3} \mathrm{He}$ and ${ }^{4} \mathrm{He}$ sequentially. The operating software performs a peak centering routine for each iteration of the procedure and then measures the peak intensity after the peak centering routine. Helium-3 is measured on the multiplier detector, whereas ${ }^{4} \mathrm{He}$ is measured on the Faraday detector. The cryostat is then heated to $-153{ }^{\circ} \mathrm{C}$, allowing the complete release of the Ne sample fraction from the cryostat's charcoal substrate.

When the He measurement procedure is complete, the MAP 215-50 and residual volume in the pipette is pumped through the flight tube's ion pump, valve $\mathrm{A}_{13}$ is closed to isolate the inlet manifold, and valve $A_{11}$ is opened to expand the Ne sample fraction from the cryostat into the inlet manifold and the expansion volume associated with valve $A_{9}$. After complete expansion, valves $\mathrm{A}_{11}$ and $\mathrm{A}_{9}$ are closed as well as isolating of the MAP 215-50 from the mass spectrometer ion pump. Both sides of the inlet pipette $\left(\mathrm{PP}_{2}\right)$ are opened while the isolation valve is closed. The remaining Ne sample fraction is exposed to an activated charcoal trap cooled with $\mathrm{LN}_{2}$, mounted in line with the sample inlet manifold. The trap is used to sorb any ${ }^{40} \mathrm{Ar}$ and $\mathrm{CO}_{2}$ in the inlet gas stream. After 30 seconds of exposure, the Ne sample fraction is expanded into the MAP 215-50 for isotopic measurement of the $\mathrm{Ne}$ isotopes $\left({ }^{20} \mathrm{Ne},{ }^{21} \mathrm{Ne}\right.$, and $\left.{ }^{22} \mathrm{Ne}\right)$ on the Faraday detector as well as for ${ }^{40} \mathrm{Ar}$ for calculation of doublet (interference with ${ }^{20} \mathrm{Ne}$ ). Carbon dioxide doublet (interference with ${ }^{22} \mathrm{Ne}$ ) is extremely small and is not included in the measurement procedure. During sample measurement of $\mathrm{Ne}$ isotopes on the MAP 215-50, the inlet manifold plus the cryostat (heated to $-153^{\circ} \mathrm{C}$ ) are purged of any residual gases by valve $A_{13}$.
Upon the completion of the Ne isotopic analysis, the flight tube is pumped by the MAP 215-50 ion pump. Valves $A_{13}$ and $A_{11}$ are closed and $A_{12}$ opened to pump out the inlet manifold. The cryostat heating element is turned off and the system is cycled to accept another extracted dissolved gas sample to the process manifold. Total run time for the procedure is approximately 2.25 hours with another 15 minutes to allow the cryostat to return to $-268^{\circ} \mathrm{C}$ operating temperature.

The sample tube is removed from the extraction line and baked in a $150{ }^{\circ} \mathrm{C}$ oven for 15 minutes. After removal from the oven, the sample is weighed and the total mass of the processed sample is calculated by subtraction of the oven-dried mass from the initial mass measured prior to mounting the copper tube on the extraction line. Both masses are recorded in the laboratory sample log book.

\section{Data Processing, Recording, and Calibration}

The standard suite of analytes run for dissolved gas analysis include reactable gases of $\mathrm{H}_{2}, \mathrm{He}, \mathrm{CH}_{4}, \mathrm{H}_{2} \mathrm{O}, \mathrm{N}_{2}, \mathrm{O}_{2}, \mathrm{Ar}$, and $\mathrm{CO}_{2}$, plus the noble gas isotopes ${ }^{132} \mathrm{Xe},{ }^{130} \mathrm{Xe},{ }^{86} \mathrm{Kr},{ }^{84} \mathrm{Kr},{ }^{40} \mathrm{Ar}$, ${ }^{38} \mathrm{Ar},{ }^{36} \mathrm{Ar},{ }^{22} \mathrm{Ne},{ }^{21} \mathrm{Ne},{ }^{20} \mathrm{Ne},{ }^{4} \mathrm{He}$, and ${ }^{3} \mathrm{He}$. There should be no $\mathrm{H}_{2} \mathrm{O}$ or $\mathrm{O}_{2}$ present in the samples, and the water vapor should be trapped back in the extraction manifold, while dissolved $\mathrm{O}_{2}$ (dissolved oxygen in the water) is removed by oxidation with the copper sampling tubing within hours of taking the dissolved gas sample. These gases are measured as an assurance that the sample tube has not leaked during shipping, storage, or sample gas extraction. Another limitation involved in data review is the presence of $\mathrm{CO}_{2}$ in the extracted gas. The calculated amount is often in excess of amounts in equilibrium with dissolved inorganic carbon present (total alkalinity). Measured $\mathrm{CO}_{2}$ levels appear to be a mix of dissolved $\mathrm{CO}_{2}$ present in the sample plus $\mathrm{CO}_{2}$ that has been generated during the dissolved gas extraction. One explanation is that the back reaction of inorganic carbon components in solution (for example. $\mathrm{H}_{2} \mathrm{O}+\mathrm{P}_{\mathrm{CO} 2} \Leftrightarrow \mathrm{H}_{2} \mathrm{CO}_{3}$ and its further dissociation to $\mathrm{HCO}_{3}$ ) add extra $\mathrm{CO}_{2}$ to the extracted gas components; however, because of extraction time and $\mathrm{pH}$ considerations, the measured $\mathrm{CO}_{2}$ value is usually not balanced by the total amount of inorganic carbon in solution. The $\mathrm{CO}_{2}$ values correlate well to alkalinity values from the samples but are not precise enough to be reported as part of the dissolved gas analysis.

All raw data from both instruments are saved digitally to the main processing computer during each cycle of the sampling procedure. The raw data are processed in a spreadsheet to derive regressed and normalized output for the noble gas isotopic measurements. The regressed data are then recorded in an official record book for each analysis by sample analysis number (increased sequentially), date of the analysis, and sample identification number. Next, the regressed data are cross referenced to the digital data saved to the computer by an analysis number and descriptor. Digital data are backed up monthly to a secondary computer. 


\section{Mass Analyzer Products 215-50 Analysis}

Data for a suite of isotopes from a single-sample extraction are collected from the MAP 215-50 in raw format and consist of measured peak heights (in cps for the channel electron multiplier (CEM)) and volts from the Faraday detector $(\mathrm{VF})$ ) coupled to time since the inlet of the gas to the mass spectrometer $\left(\mathrm{T}_{0}\right)$ for each iteration of a measurement procedure. The CEM data can range from 0.5 to 2,000,000 cps in the linear range of the detector, while the Faraday data can range from 0.0005 to $11 \mathrm{VF}$ for linear range of the detector. The data are regressed to the $\mathrm{T}_{0}$ value for each isotope measured (fig. 2). The only data points that are removed from the raw dataset, to achieve a best fit to the linear regression, are associated with the ${ }^{3} \mathrm{He}$ data regression or times when the CEM is affected by radio frequency interference (the spin up of bushings from the fan motor in a heat gun can be detected by the CEM, producing a spike in the output signal from the $\mathrm{CEM}$ ). For the $\mathrm{Xe}$ and $\mathrm{Kr}$ procedures, the regression of the data is linear the first three to four iterations of the runs; more cycles in the procedure are affected by ion depletion in the flight tube, which is an asymptotic decay curve of the data acquisition against time. Fitting the decay curve to a full set of $5-10$ cycles in the procedure introduces large uncertainty in the regressed $\mathrm{T}_{0}$ value for the gas, so only the linear range of the data ( $3-4$ cycles) is used to produce the $T_{0}$ values for ${ }^{132} \mathrm{Xe}$, ${ }^{130} \mathrm{Xe},{ }^{86} \mathrm{Kr}$, and ${ }^{84} \mathrm{Kr}$. Standard error for the regression is typically less than 1 percent (often less than 0.3 percent) of the $T_{0}$ value for the measured isotopes (fig. 2).

\section{Residual Gas Analyzer 200 Dynamic Analysis}

For the active gas data from a single sample measured by the RGA200, the baseline data (in amperes) are corrected for fragmentation factors and are subtracted from primary masses in the spectra (for example, $\mathrm{CO}$ fragmentation from $\mathrm{CO}_{2}$ subtracted from $\mathrm{N}_{2}$ ) and then calibrated; ionization factors are applied to the fragment-corrected data. The calibrated ionization factors are derived from earlier calibration runs of pure gases such as $\mathrm{CH}_{4}$ and $\mathrm{CO}_{2}$ mixed with an air standard at varying quantities to determine ionization correction factors relative to $\mathrm{N}_{2}$. Figure 3 shows the results of the ionization-corrected data in mole percent of composition of gases of air $\left(\mathrm{O}_{2}, \mathrm{~N}_{2}\right.$, and $\left.\mathrm{Ar}\right)$ mixed with varying quantities of $\mathrm{CH}_{4}$ and $\mathrm{CO}_{2}$ mixed as both pure $\mathrm{CH}_{4}$ and $\mathrm{CO}_{2}$ and mixtures of $\mathrm{CH}_{4}$ and $\mathrm{CO}_{2}$.

The results of the corrected active gas analysis can be converted to mole percent by simply dividing the analyte gas by the sum of the total gases present (total pressure), termed the summation method for calculation. From the calibration runs, corrected data are generally within a standard error or less than 1 percent of the predicted mole fraction but can climb to as high as 8 percent depending on the signal intensity of the gas. This calculated mole fraction of gas can be multiplied by the total gas volume measured by the processing line capacitance manometers to give total volume of gas present. This value is divided by total mass of sample extracted to obtain a concentration of dissolved gas per gram of water $\left(\mathrm{cm}^{3} \mathrm{STP} / \mathrm{g}_{(\mathrm{H} 2 \mathrm{O})}\right)$. Another ratio-sensitive calculation for the gases uses corrected values of select gas normalized to Ar measured on the RGA200 and then multiplied by the measured Ar value from the MAP 215-50. The advantage of this calculation is that error propagation is decreased by using the ratio error of the RGA (for example, $\mathrm{N}_{2} / \mathrm{Ar}$ measured is $83.60 \pm 0.3$ when $\mathrm{Ar}$ is greater than $5 \times 10^{-11}$, coupled with the error of the MAP 215-50 for the Ar measurement (1-2 percent).

\section{Calibration of Mass Spectrometer Measurements}

\section{Mass Analyzer Products 215-50}

Calibration of digital data from the MAP 215-50 to known concentration data is accomplished by running a known laboratory standard with a fixed volume and known temperature by the same process that we run extracted sample gas in the extraction line. This procedure is performed once on a daily basis prior to running any samples. Affixed to the process manifold (fig. 1) is a closed tank of the in-house gas standard connected to the manifold by a calibrated pipette. The known laboratory standard consists of an in-house supply of a factory-generated air standard of known composition (close to that of values listed for U.S. Standard Atmosphere [National Ocean and Atmospheric Administration, 1976], calibrated by interlaboratory calibration studies, collected air samples, and synthetic air saturated water samples [see QA and QC section Generation of In-House Synthetic Air Equilibrated Water]). The standard is referred to as Riverside Air Standard (RAS), and the pressure inside the standard volume is measured continuously by a 1,000-torr range capacitance manometer. The temperature is measured by a chromel-alumel (type $\mathrm{K}$ ) thermocouple attached to the standard volume. Aliquots (up to five individual) of the RAS can be dispensed into the vacuum manifold by the pipette in order to determine instrument responses to varying amounts of gas contained into process manifold plus the extraction manifold. Amounts of gas contained are calculated by the ideal gas law and the equation:

$$
\begin{aligned}
\mathrm{V}_{\mathrm{G}} & =\left(\left(\mathrm{V}_{\mathrm{pip}} * \mathrm{P}_{\mathrm{ras}}\right) /\left(\left(\mathrm{T}_{\mathrm{ras}}+273.15\right)\right.\right. \\
& * 82.057) * 22.414 * 1000 * \mathrm{P}_{\mathrm{G}}
\end{aligned}
$$

where

$$
\begin{aligned}
\mathrm{V}_{\mathrm{G}} & =\text { Volume amount of gas (cubic centimeters) } \\
\mathrm{V}_{\text {pip }} & =\text { Volume of pipette (cubic centimeters) } \\
\mathrm{P}_{\text {ras }} & =\text { Pressure of the RAS (in atmospheres) } \\
\mathrm{T}_{\mathrm{ras}} & =\text { Temperature of the RAS (degrees Celsius) } \\
\mathrm{P}_{\mathrm{G}} & =\text { Calibrated partial pressure of the gas in the } \\
& \text { RAS (mole fraction) } \\
82.057 & =\text { Universal gas constant }\left(\mathrm{cm}^{3}\right. \text { atmospheres } \\
22.414 & \left.\quad \mathrm{~K}^{-1} \mathrm{~mol}^{-1}\right) \\
& \text { Molar volume at } 1 \text { atmosphere, } 0{ }^{\circ} \mathrm{C} \\
& \quad(\text { McNaught and Wilkinson, 1997) }
\end{aligned}
$$



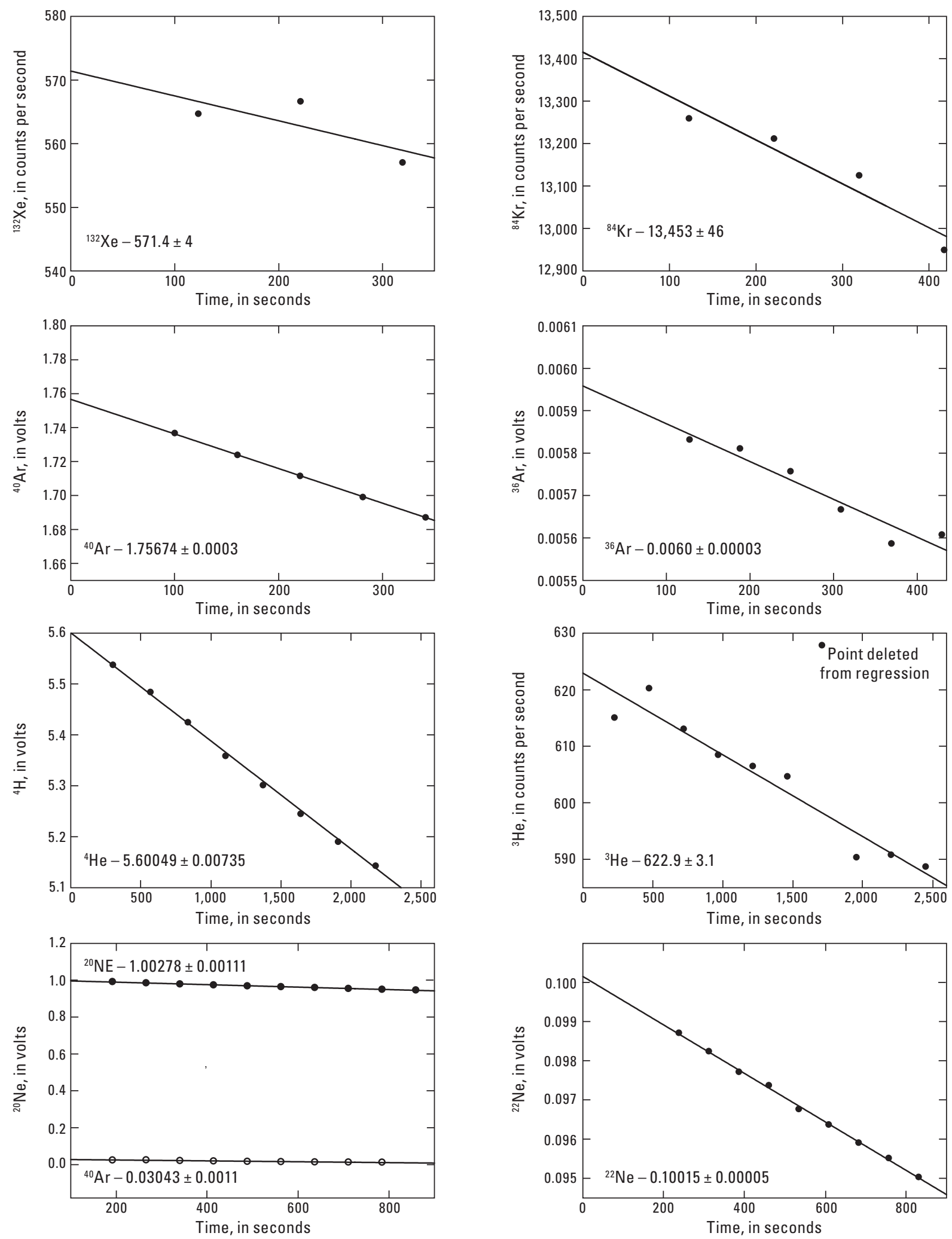

Figure 2. Regression data for the isotopes ${ }^{3} \mathrm{He},{ }^{4} \mathrm{He},{ }^{20} \mathrm{Ne},{ }^{22} \mathrm{Ne},{ }^{40} \mathrm{Ar},{ }^{36} \mathrm{Ar},{ }^{84} \mathrm{Kr}$, and ${ }^{132} \mathrm{Xe}$. Raw data are presented from five separate analyses using a single sample run from the Mass Analyzer Products 215-50. Data are presented as detector output with time, with a linear regression performed to resolve $T_{0}$ value for the isotope with a 1-sigma error of deviation from the linear regression. For ${ }^{20} \mathrm{Ne}$, the measured ${ }^{40} \mathrm{Ar}$ peak is also presented; the ${ }^{40} \mathrm{Ar}$ doublet $(\approx 2$ percent of the argon-40 value) has no effect on the ${ }^{20} \mathrm{NE}$ value within measurement precision. ${ }^{3} \mathrm{He}$, helium-3; ${ }^{4} \mathrm{He}$, helium-4; ${ }^{20} \mathrm{Ne}$, neon-20; ${ }^{22} \mathrm{Ne}$, neon-22; ${ }^{40} \mathrm{Ar}$, argon-40; ${ }^{36} \mathrm{Ar}$, argon-36; ${ }^{84} \mathrm{Kr}$, krypton-84; and ${ }^{132} \mathrm{Xe}$, xenon- 132. 


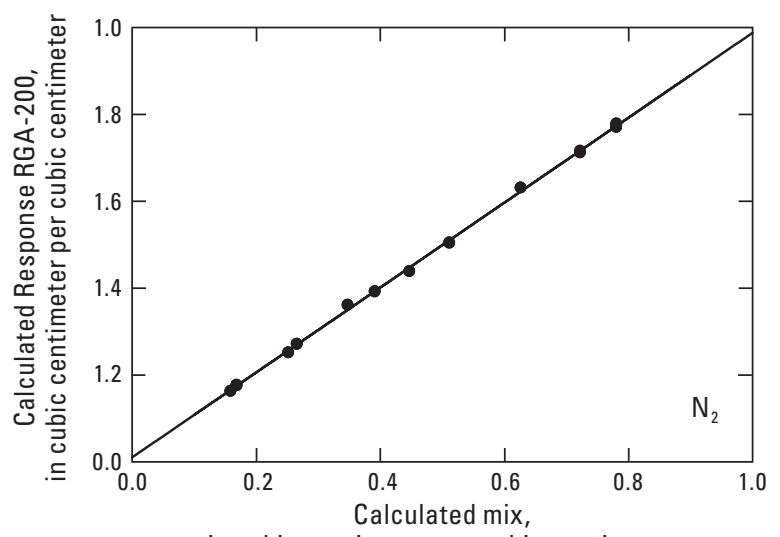

in cubic centimeter per cubic centimeter

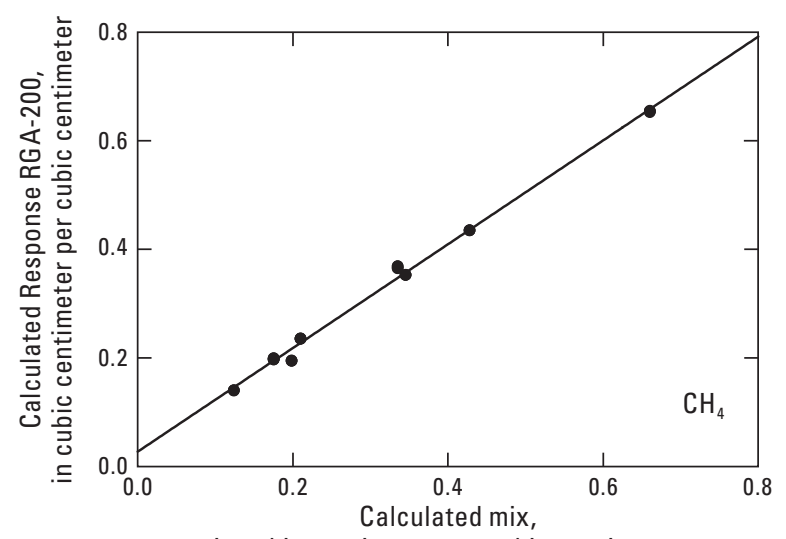

in cubic centimeter per cubic centimeter

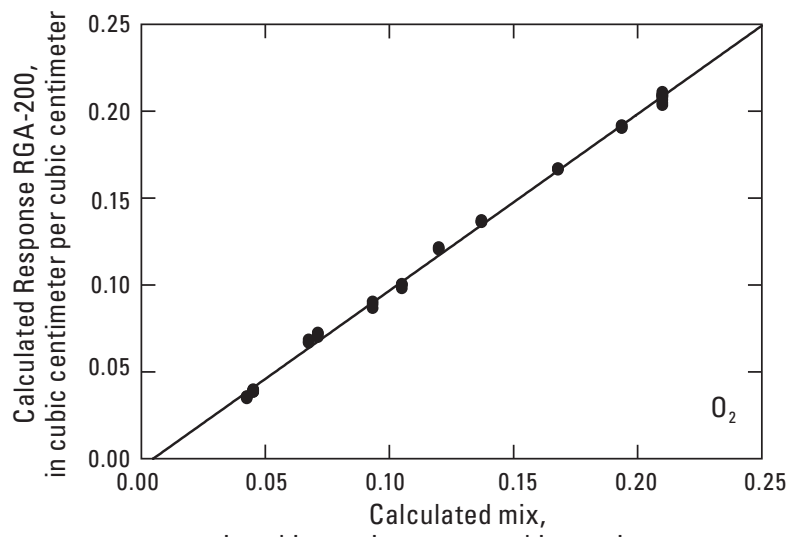

in cubic centimeter per cubic centimeter

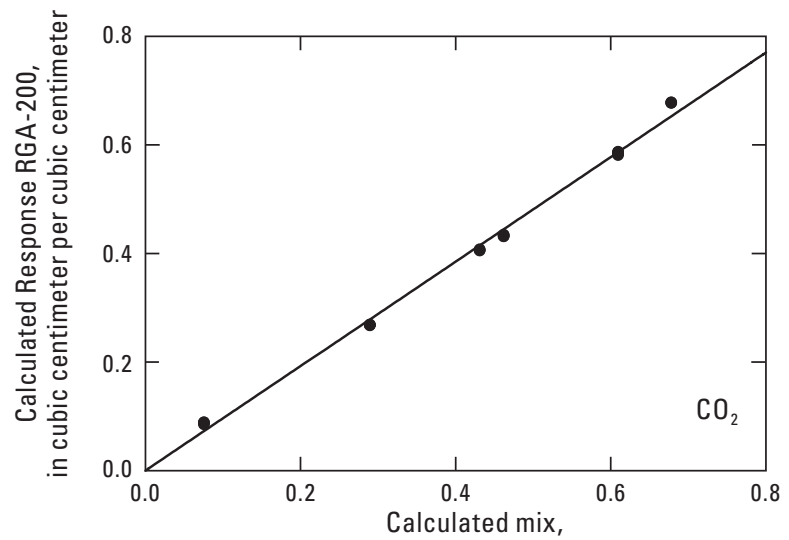

in cubic centimeter per cubic centimeter

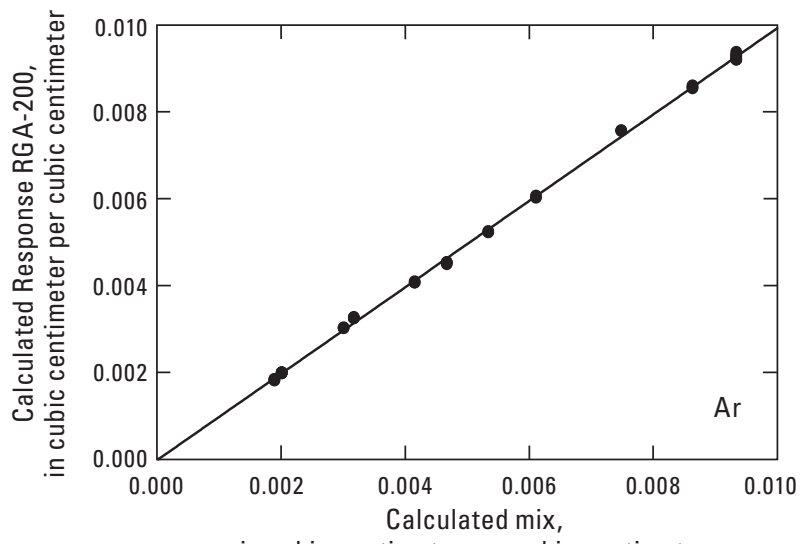

in cubic centimeter per cubic centimeter

Figure 3. Results for the gas calibration of the Residual Gas Analyzer Model 200 (RGA200), quadrupole mass spectrometer. The calculated response of the RGA200 is shown with varying mixtures of air $\left(\mathrm{N}_{2}, \mathrm{O}_{2}\right.$, and $\left.\mathrm{Ar}\right)$ with $\mathrm{CH}_{4}$ and $\mathrm{CO}_{2}$. Calculated mole fractions $\left(\mathrm{cm}^{3} / \mathrm{cm}^{3}\right)$ using computed ionization efficiencies of gas normalized to $\mathrm{N}_{2}$ show a linear response with concentration variation of gas mixtures. $\mathrm{N}_{2}$, nitrogen; $\mathrm{O}_{2}$, oxygen; $\mathrm{CH}_{4}$, methane; $\mathrm{CO}_{2}$, carbon dioxide; $\mathrm{Ar}$, argon; $\mathrm{cm}^{3} / \mathrm{cm}^{3}$, cubic centimeter per cubic centimeter. 
The ability to dispense multiple shots of RAS from the pipette allows for the calibration of multiple volumes (amounts) of isotopes against a range of instrument responses, creating a calibration curve for instrument response to analyte abundance. In figure 4, actual set calibration curves are given from a set of standard analyses $(\mathrm{n}=16$, over a range from 0 to 5 aliquots of RAS). The curves are plotted in order to calculate total noble gas abundance by the response of a select isotope and the total volume of the gas produced from the sample extraction against the response from the 1- and 10-torr range capacitance manometers. Calculated regressions of the data produce linear responses (as predicted by the linear ranges of the detectors) of the measured values and regress well to near zero conditions which can be defined either as zero for the curve or be defined by a blank run of the sample analysis procedure. One-sigma deviations of the standard data from the calibration curves are well represented by $\mathrm{R}^{2}$ values of 0.999 for any one curve; the actual error associated will depend on the amount of sample signal associated with any one calculated calibration curve, typically falling within $0.5-2$ percent of the known value depending on the analyte.

Noble gas abundance in water samples is typically not similar to air-like concentrations of noble gases. Due to solubility conditions of water samples, gas compositions of noble gases are enriched in heavier noble gases $(\mathrm{Kr}$ and $\mathrm{Xe}$ ) because of their higher solubility in water. When analyzing watersourced dissolved gas, amounts of $\mathrm{He}, \mathrm{Ne}$, and $\mathrm{Ar}$ are within the limits as bounded by the calibration runs for the samples; data for $\mathrm{Kr}$ and Xe typically are not (fig. 4). Calibration curves for $\mathrm{Kr}$ and $\mathrm{Xe}$ are extrapolated to higher values, and because of the linearity of the CEM (up to 2 million cps), values measured below 2 million cps are considered valid for the linear range of the detector. Further evaluation of the extrapolated linearity is evaluated by use of synthetic water standards (see section on QA and QC section Generation of In-House Synthetic Air Equilibrated Water).

Sample responses are multiplied by the slope of the calibration curves plus the intercept and then divided by the measured mass of the sample to produce a concentration of the analyte per unit mass of water from the sample. The gas is quoted in units of cubic centimeters (volume) at standard pressure and temperature per gram of water $\left(\mathrm{cm}^{3} \mathrm{STP} / \mathrm{g}_{\mathrm{H} 2 \mathrm{O}}\right)$. Gases are reported as elemental concentrations of gas to be easily compared to solubility data which is published as elemental concentrations (Weiss [1970, 1971], Weiss and Kyser [1978], Clever [1979], Smith and Kennedy [1983]). A summary of this calculation is presented in table 1. Minimum and maximum values for each analyte are presented in terms of the instrument measurement parameters along with the calculated standard error for the analyte. The reduced data are compared to sample analysis by normalizing the data by typical sample volumes of water analyzed in the procedure. The maximum for $\mathrm{He}$ is left at $28 \mathrm{~V}$ (within the range of the calibration curve) when the procedure allows for an open-ended value that can be greater than $10,000 \mathrm{~V}$, accommodated by the expansion procedure used for helium measurement. The table lists the minimum and maximum values that can be measured for the analytes (within sample mass requirements of 13 grams (g), $16 \mathrm{~g}$ and $40 \mathrm{~g}$ ) in comparison to calculated air-saturation solubility values (Weiss [1970, 1971], Weiss and Kyser [1978], Clever [1979], and Smith and Kennedy [1983]) at sea level $[\mathrm{P}=760$ torr $]$ and one mile in altitude $[\mathrm{P}=626$ torr $]$ ) at temperatures of $2{ }^{\circ} \mathrm{C}$ and $30^{\circ} \mathrm{C}$.

Isotopic ratios of ${ }^{20} \mathrm{Ne} /{ }^{22} \mathrm{Ne},{ }^{21} \mathrm{Ne} /{ }^{22} \mathrm{Ne},{ }^{38} \mathrm{Ar} /{ }^{36} \mathrm{Ar}$, ${ }^{40} \mathrm{Ar} /{ }^{36} \mathrm{Ar},{ }^{86} \mathrm{Kr} /{ }^{84} \mathrm{Kr}$, and ${ }^{130} \mathrm{Xe} /{ }^{132} \mathrm{Xe}$ are produced by mathematical calculation of the ratio of the $\mathrm{T}_{0}$ values for each gas taken from each separate analysis (see table 1). Because the isotopes in each ratio are measured on a similar detector, there is no need to convert for sensitivity variations in data to determine abundance ratio. Maximum and minimum values presented in table 1 are based on ranges in the detectors used for the measurement. These ranges represent a much wider possible variation in the isotopic pairs than is observed in natural samples.

For ${ }^{3} \mathrm{He} /{ }^{4} \mathrm{He}$, the two isotopes are measured on the CEM and Faraday detectors for the MAP 215-50. Data for the sample isotopic ratio are normalized to the measured RAS isotopic ratio and multiplied by the known ${ }^{3} \mathrm{He} /{ }^{4} \mathrm{He}$ ratio in the atmosphere $\left(1.384 \times 10^{-6}\right)$.

$$
\mathrm{R}_{\text {sample }}=\mathrm{R}_{\text {measured }} / \mathrm{R}_{\mathrm{RAS}} * 1.384 \times 10^{-6}
$$

where

$$
\begin{aligned}
& \mathrm{R}_{\text {sample }} \quad=\text { Absolute }{ }^{3} \mathrm{He} /{ }^{4} \mathrm{He} \text { ratio of the sample } \\
& \mathrm{R}_{\text {measured }} \quad={ }^{3} \mathrm{He}(\mathrm{CEM}) /{ }^{4} \mathrm{He} \text { (Faraday) for the sample } \\
& \text { ( } \mathrm{T}_{0} \text { values) } \\
& \mathrm{R}_{\mathrm{RAS}} \quad={ }^{3} \mathrm{He}(\mathrm{CEM}) /{ }^{4} \mathrm{He} \text { (Faraday) average RAS } \\
& \text { value }(<0.5 \text { percent variability in value) } \\
& 1.384 \times 10^{-6}=\text { Absolute }{ }^{3} \mathrm{He} /{ }^{4} \mathrm{He} \text { of the standard (absolute } \\
& \text { ratio in air [Clarke and others, 1976]) }
\end{aligned}
$$

A simpler form of the equation neglects the multiplication of the absolute value of ${ }^{3} \mathrm{He} /{ }^{4} \mathrm{He}$ in air and produces the value for $R_{\text {sample }}$ as $R / R_{A}$ or the sample ratio normalized to atmospheric value.

\section{Residual Gas Analyzer 200}

For the RGA200, running a RAS is typically a confirmation that the original ionization factors calibrated (see Residual Gas Analyzer 200 section of this report) are consistent with the original calibration of the quadrupole mass spectrometer. The ratios of $\mathrm{N}_{2} / \mathrm{Ar}$ and $\mathrm{N}_{2} / \mathrm{O}_{2}$ are calculated from the dynamic run, noted over the use in the calibration standards, and compared to that in the multigas calibration runs (see table 1). Since $\mathrm{CO}_{2}$ values are in the parts per million range in the RAS, little to no 

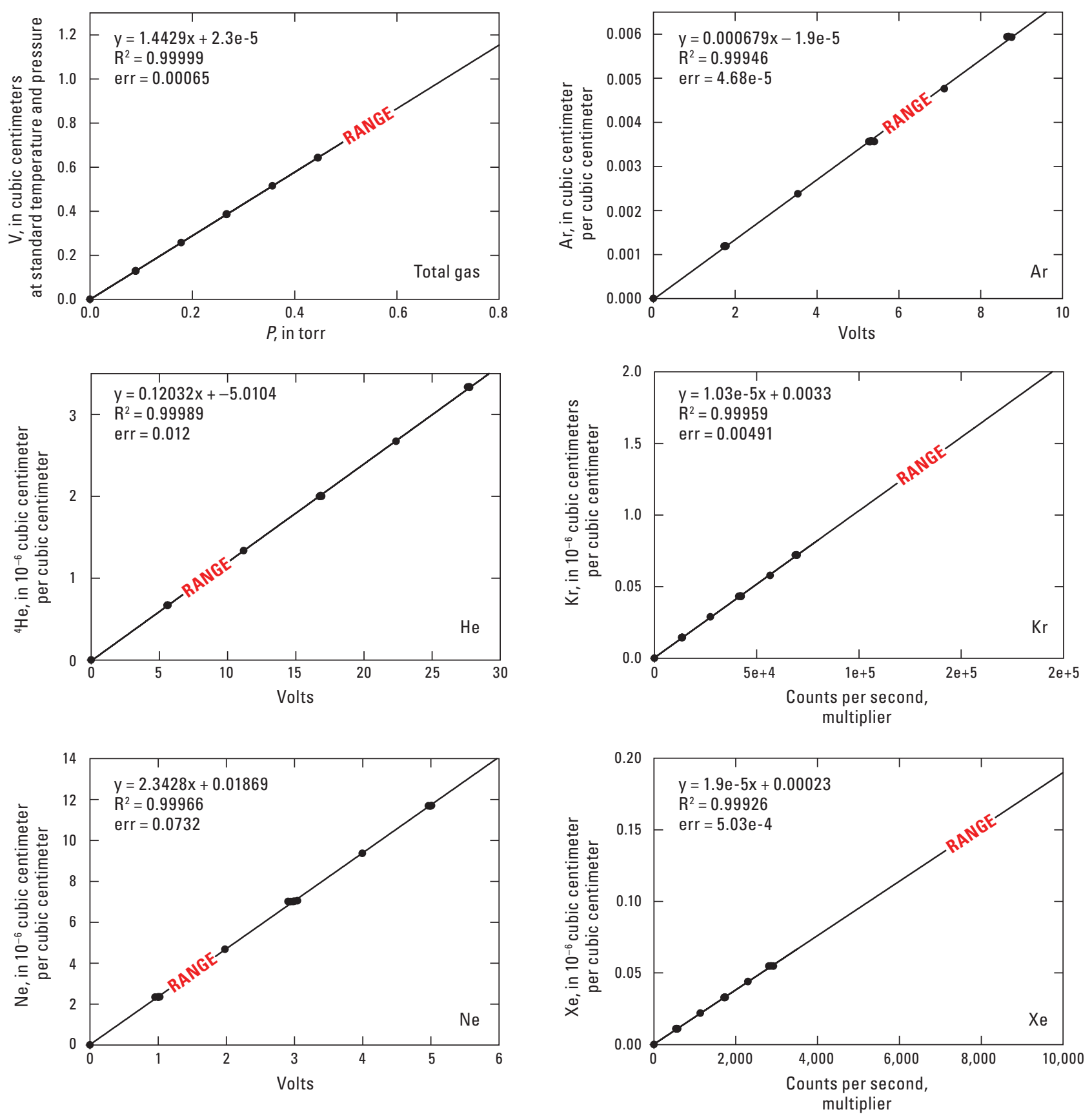

Figure 4. Calibration curves of Riverside Air Standard (RAS) concentration to MAP 215-50 machine response. The computed concentrations (elemental abundance) of the RAS are plotted against the instrument response of select isotopic value. Plots contain 18 data points each, and computed linear regressions (calibration curve) for each elemental abundance are given with $R^{2}$ value and 1-sigma deviation from the regression. Also shown is the capacitance manometer value against total volume of the RAS cubic centimeters at standard temperature and pressure ( $\left.\mathrm{cm}^{3} \mathrm{STP}\right)$ for calculations used in the RGA200 gas analysis. Range identifies the typical range of machine responses for air-saturated water samples run by the procedure. Ar, argon; He, helium; $\mathrm{Kr}$, krypton; $\mathrm{Ne}$, neon; $\mathrm{Xe}$, xenon; $\mathrm{cm}^{3} \mathrm{STP}$, cubic centimeter at standard temperature and pressure; $\mathrm{P}$, pressure; CPS, counts per second; $\mu \mathrm{cm}^{3} / \mathrm{cm}^{3},\left(10^{-6} \mathrm{~cm}^{3} / \mathrm{cm}^{3}\right)$; err, error. 
Table 1. Instrument precision for $\mathrm{He}, \mathrm{Ne}, \mathrm{Ar}, \mathrm{Kr}$, and $\mathrm{Xe}$.

[He, helium; Ne, neon; ${ }^{20} \mathrm{Ne}$, neon-20; ${ }^{22} \mathrm{Ne}$, neon-22; Ar, argon; ${ }^{36} \mathrm{Ar}$, argon-36; ${ }^{38} \mathrm{Ar}$, argon-38; ${ }^{40} \mathrm{Ar}$, argon-40; Kr, krypton; ${ }^{84} \mathrm{Kr}$, krypton-84; ${ }^{86} \mathrm{Kr}$, krypton-86; Xe, xenon; ${ }^{130} \mathrm{Xe}$, xenon-130; ${ }^{132} \mathrm{Xe}$, xenon-132; $\mathrm{VF}$, volts measured on the Faraday detector; $\mathrm{cps}$, counts per seconds as measured on the channel electron multiplier; $\mathrm{g}$, gram; $\mathrm{cm}^{3} \mathrm{STP}$, cubic centimeter at standard temperature and pressure; $\mathrm{cm}^{3} \mathrm{STP} / \mathrm{g}$, cubic centimeter at standard temperature and pressure per gram of water; *, this measurement is open to much higher values due to the re-expansion of the helium sample, $28 \mathrm{VF}$ is presented as a maximum for the calibration curve presented figure 4; "Error**, the standard error of the predicted $y$-value for each $x$ in the regression based on the calibration curves in figure 4; the standard error is a measure of the amount of error in the prediction of $y$ for an individual $x$. ."; $\mathrm{cm}^{3} \mathrm{STP} / \mathrm{g}\left(\mathrm{H}_{2} \mathrm{O}\right)^{* * *}$, total volume of cubic centimeter at standard temperature and pressure per gram of water without dissolved oxygen; ****, values listed in Porcelli and others (2002)], Isotopic ratios are presented with average and standard deviation based on replicate analysis of 16 Riverside Air Standard (RAS) samples; ${ }^{\circ} \mathrm{C}$, degrees Celsius]

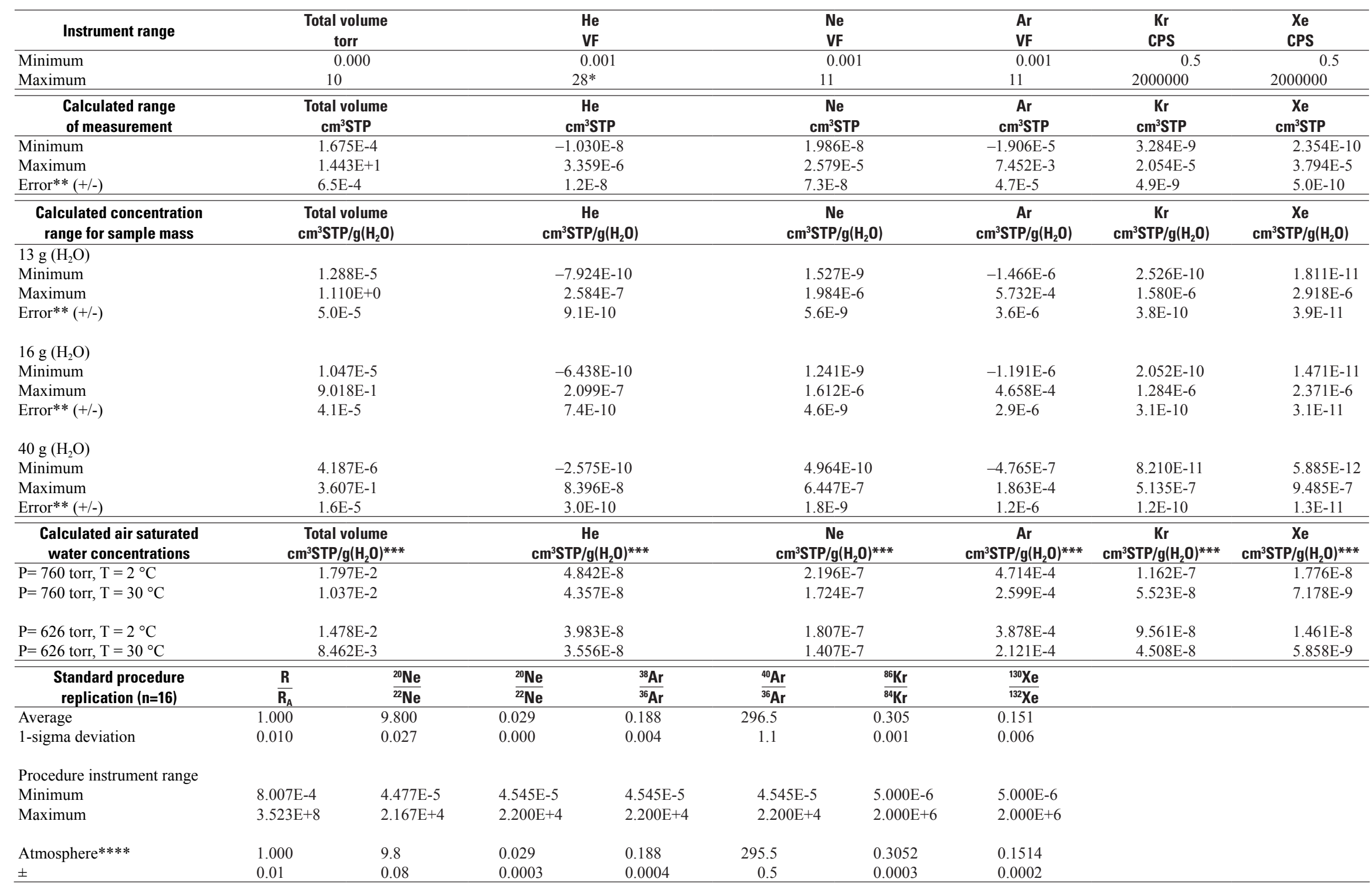


correcting is noted for $\mathrm{CO}$ and $\mathrm{O}_{2}$ fragments in the analysis. As the gas ratios are within error for the original ratios in the multigas calibrations, the fractionation factors and ionization calibrations are confirmed to be the same as the multigas calibrations. In general, the calculation as outlined in the Residual Gas Analyzer 200 Dynamic Analysis section of this report is:

$$
\left.\mathrm{C}_{\mathrm{i}}=\left(\left(\mathrm{A}_{\mathrm{i}}-\mathrm{F}\right) * \mathrm{I}_{\mathrm{Fi}} / \Sigma\left(\left(\mathrm{A}_{\mathrm{i}-\mathrm{n}}\right)-\mathrm{F}\right) * \mathrm{I}_{\mathrm{Fi}}\right)\right) * \mathrm{~V} / \mathrm{M}
$$

where

$$
\begin{aligned}
& \mathrm{C}_{\mathrm{i}} \quad=\text { Concentration gas species } \mathrm{i} \\
& \left(\mathrm{cm}^{3} \mathrm{STP} / \mathrm{g}_{\mathrm{H} 2 \mathrm{O}}\right) \\
& \mathrm{A}_{\mathrm{i}} \quad=\text { Amperage reading from quadrupole } \\
& \text { mass spectrometer } \\
& \mathrm{F}=\text { Known fragmentation factors of other } \\
& \mathrm{I}_{\mathrm{Fi}} \quad=\text { Ionization factor for gas species } \mathrm{i} \\
& \Sigma\left(\left(\mathrm{A}_{\mathrm{i}-\mathrm{n}}-\mathrm{F}\right) * \mathrm{I}_{\mathrm{Fi}}\right) \quad=\text { Sum of all peaks measured (in }
\end{aligned}
$$

Data shown in figure 3 and table 1 were processed in this calculation. This equation mainly produces data for $\mathrm{CH}_{4}, \mathrm{~N}_{2}$, and Ar measured in the dissolved gas samples (see Residual Gas Analyzer 200 section of this report). An alternative calculation that can be used for $\mathrm{N}_{2}$ would include the use of the measured value of Ar from the MAP 215-50. Data shown in figure 3 have been processed in this calculation:

$$
\mathrm{C}_{\mathrm{N} 2}=\left(\left(\mathrm{A}_{\mathrm{N} 2}-\mathrm{F}\right) /\left(\mathrm{A}_{\mathrm{Ar}} * \mathrm{IF}_{\mathrm{Ar}}\right)\right) * \mathrm{Ar}_{\mathrm{MAP} 215-50}
$$

where

$$
\begin{aligned}
& \mathrm{C}_{\mathrm{N} 2}=\text { Concentration of } \mathrm{N}_{2}\left(\mathrm{~cm}^{3} \mathrm{STP} / \mathrm{g}_{\mathrm{H} 2 \mathrm{O}}\right) \\
& \mathrm{A}_{\mathrm{N} 2} \quad=\text { Amperage } \mathrm{N}_{2} \text { on quadrupole mass } \\
& \text { spectrometer } \\
& \mathrm{F} \quad=\text { Fragmentation factor for } \mathrm{N}_{2}(\mathrm{CO} \text { fragment } \\
& \text { from } \mathrm{CO}_{2} \text { measured) } \\
& \mathrm{A}_{\mathrm{Ar}} \quad=\text { Amperage Ar on quadrupole mass } \\
& \mathrm{IF}_{\mathrm{Ar}}=\text { Ionization factor for } \mathrm{Ar} \\
& \mathrm{Ar}_{\mathrm{MAP}-215-50}=\text { Measured Ar concentration }\left(\mathrm{cm}^{3} \mathrm{STP} / \mathrm{g}_{\mathrm{H} 2 \mathrm{O}}\right) \\
& \text { from MAP 215-50 }
\end{aligned}
$$

The advantage to this calculation is the decreased error associated with the measurement of the $\mathrm{N}_{2}$-to-Ar ratio on the quadrupole mass spectrometer (typically $<2$ percent), and the decreased error with the measured Ar from the MAP 215-50 (typically 1-2 percent) without the inclusion of the error associated with the other gas species in the RGA run, which could be as high as 5-percent error and also could include the calculated ionization factor of Ar generated from the RAS data during the standard runs.

Table 2 shows a sample calculation from the RGA200 using the 14 separate RAS analyses expressed as a mole fraction of the gas. Simple error propagation for this type of calculation would include error within the capacitance manometer $(<0.2$ percent, not shown on table 2) coupled with the calculated error of the RGA measurement based on signal intensity, weighing error of the sample (less than 0.05 percent), and uncertainty in calibration of ionization factors for the dynamic run on the RGA. Oxygen is much more unstable in the sample runs with a variability of the calculated ionization factor of 12 percent, whereas the Ar ionization varies less than 2 percent for the 14 analyses. Using the summation method of calculation, the $\mathrm{O}_{2}$ values vary as high as 8 percent, affecting the values of $\mathrm{N}_{2}$ and Ar from the use of $\mathrm{O}_{2}$ in the summation equation. Using the ratio-sensitive method, both $\mathrm{N}_{2}$ and Ar decrease in variation in the runs due to the low inherent error associated with the Ar analysis on the MAP 215-50, but in this case, the actual decrease in the error is minimal (table 2). The addition of $\mathrm{CO}_{2}$ and $\mathrm{CH}_{4}$ to the sample gas generally increases the uncertainty in the summation technique (variation in ionization factors for $\mathrm{CO}_{2}$ and $\mathrm{CH}_{4}$ ) and can cause errors in as much as 5 percent for $\mathrm{N}_{2}$. Using the ratio-sensitive calculation, only the fragmentation factor of $\mathrm{CO}_{2}$ (CO or mass 28) accounts for the variation in $\mathrm{N}_{2}$ values. This typically reduces the error for $\mathrm{N}_{2}$ to less than 3 percent.

Table 2. Calculation method for nitrogen, oxygen, and argon from the quadrupole mass spectrometer data.

[IF, ionization factors; $\mathrm{N}_{2}$, nitrogen; $\mathrm{O}_{2}$, oxygen; $\mathrm{Ar}$, argon; $\mathrm{cm}^{3} / \mathrm{cm}^{3}$, cubic centimeter per cubic centimeter; \%, percent; *, values listed in Porcelli and others (2002)]

\begin{tabular}{lccc}
\hline \multicolumn{1}{c}{ Ionization factors } & $\mathbf{I F}_{\mathbf{N 2}}$ & $\mathbf{I F}_{\mathbf{0 2}}$ & $\mathbf{I F}_{\mathbf{A r}}$ \\
\hline Average & 1 & 4.295 & 1.417 \\
1-sigma deviation & -- & 0.528 & 0.018 \\
$\mathrm{n}=14$ & & $12.3 \%$ & $1.3 \%$ \\
\hline \hline \multicolumn{1}{c}{ Summation method } & $\mathbf{I F}_{\mathbf{N 2}}$ & $\mathbf{I F}_{\mathbf{0 2}}$ & $\mathbf{I F}_{\mathbf{A r}}$ \\
Average & $\mathbf{c m}^{3} / \mathbf{c m}^{3}$ & $\mathbf{c m}^{3} / \mathbf{c m}^{3}$ & $\mathbf{c m}^{3} / \mathbf{c m}^{3}$ \\
1-sigma deviation & 0.780 & 0.211 & 0.009 \\
n=14 & 0.018 & 0.018 & 0.000 \\
\hline Ratio-sensitive method & $2.3 \%$ & $8.6 \%$ & $2.4 \%$ \\
\multicolumn{1}{c}{ for $\mathbf{N}_{\mathbf{2}}$} & $\mathbf{I F}_{\mathbf{N 2}}$ & & $\mathbf{I F}_{\mathbf{A r}}$ \\
Average & $\mathbf{c m}^{3} / \mathbf{c m}^{3}$ & & $\mathbf{c m}^{3} / \mathbf{c m}$ \\
1-sigma deviation & 0.777 & & 0.009 \\
n=14 & 0.014 & & 0.000 \\
Atmosphere* & $1.8 \%$ & & $1.2 \%$ \\
& 0.781 & 0.209 & 0.009 \\
& & & 0.000 \\
\hline
\end{tabular}




\section{Quality Assurance and Quality Control}

The purpose of a quality assurance and quality control (QA and QC) program for this procedure is to ensure that the data reported from the laboratory are accurate and reproducible for the USGS NGL and other laboratories which do similar analyses. In terms of the approach, the QA and QC program faces many different requirements other than just instrument operation and calibration. The extraction procedure must fulfill the requirement to extract dissolved gas completely for each sample; sampling procedures must produce reproducible data for each sample taken; and data handling must follow guidelines to produce accurate data. This section details the best available practices to ensure that the instrument and extraction procedures produce accurate and reproducible data. The variability in sampling issues, which can be minimized, cannot be addressed in the context of a QA and QC program for the laboratory. Sampling conditions and even sampling procedures can be, in some cases, the greatest variability in the comparison of dissolved noble gas data from one laboratory to another. The main goal of our QA and QC program is to ensure that the instrument and laboratory procedures are as accurate and reproducible as possible through a series of crosschecks that prove the analytical procedures are correct. The strength of this procedure is the use of multiple checks on a day-to-day basis by an operator who oversees the equipment operation, which minimizes possible lost time and samples to sporadic errors.

\section{Verification of RAS during Sample Runs}

The first check that is performed for the QA and QC procedure is the evaluation of the reproduction of the standard throughout the measurement of a set of samples. One RAS is run for every two-to-three unknown sample runs, a typical daily load for the instrumental procedure. The standard is run first in the queue of unknowns and compared to calibration curves within the preceding sample stream. In a simple way, this indicates to the operator that the instrument is operating (both vacuum system and mass spectrometers) within tolerances of the procedure and allows for a running error calculation to be performed for each standard run on the system. This is often the case with running the mass spectrometer for months at a time; the calibration curves are consistent and require no changes to the procedure or equipment. In the case when the standard run falls below expectations of error associated with the procedure, the system is evaluated for hardware problems such as transmitting valves or failing pipettes or instrumental problems such as the ion-source tuning coming out of alignment. The running of unknowns is ceased until the error is detected and corrected. A new set of calibration curves is generated for the instrument prior to running any unknowns. Although this represents only a first line and most common use of the QA and QC program, this analysis of the repeatability of an internal standard is followed on a daily basis by the instrument operator and is typically where problems are first identified.

\section{Air Verification of In-House Standard}

The use of an enclosed, calibrated standard (RAS) for the generation of the calibration curves for the procedure is advantageous to show repeatability and instrument tuning, but the RAS also needs to be crosschecked from time to time by comparison to an atmospheric sample taken somewhat locally to the laboratory. In general, the atmosphere is considered to be well mixed and a well-characterized reservoir with a uniform noble gas composition; it is only affected by local contamination from anthropogenic and natural sources. An example of this is the building air in the laboratory which is not close to that of the atmosphere, but the air is modified by the venting of $\mathrm{He}$ and $\mathrm{Ar}$ from instruments (stable isotope mass spectrometers, gas chromatographs, and inductively coupled plasma mass spectrometry [ICP-MS] instruments). As part of our QA and QC program, we obtain air samples far from urban areas and run these air samples to check the mole fraction calibration of our RAS.

The laboratory has designated three possible sample sites for collection of air samples: Loveland Pass, Colo.; Hanging Lake, Mt. Evans, Colo.; and Green Mountain, Lakewood, Colo. These are sites where air patterns represent well-mixed areas that are least affected by any possible source of noble gas contamination. An evacuated stainless steel cylinder with an inlet and outlet valve is purged with 3 to 5 volumes of sample air by a small diaphragm pump. The valves are closed, and the cylinder is transported to the laboratory where it is mounted on the extraction manifold. Aliquots (between 0.1 and $0.5 \mathrm{~cm}^{3} \mathrm{STP}$ in volume) are run as an unknown using the dissolved water procedure. Data are processed in the same manner as the dissolved gas analysis, but instead of normalizing the measured data to mass of the sample, the measured data are normalized to the volume (measured by the capacitance manometer) and presented as a molar ratio of the gas. Data from two separate verification runs plus a typical working laboratory atmosphere (USGS Reston Groundwater Dating Laboratory, formerly the USGS Chlorofluorocarbons Laboratory) are presented in table 3 . The earlier verification runs (2007) presented concentration data as elemental abundance while later runs (2014) present an isotopic composition of the sample. The sample from laboratory air shows that the composition is close to that of the atmosphere but contains enrichment of He. The measured standard air samples compose what is accepted of dry U.S. Standard Atmosphere 1976, as defined by National Ocean and Atmospheric Administration (1976) and Ozima and Podesek (2001). (Note that since samples are exposed to the two ethanol slush traps, water associated with relative humidity during sampling is removed from the analysis.) Both runs from 2007 and 2014 are in close agreement to the composition 
Table 3. Summary of air verification of in-house standard.

$\left[\mathrm{N}_{2}\right.$, nitrogen; $\mathrm{O}_{2}$, oxygen; He, helium; Ne, neon; Ar, argon; Kr, krypton; Xe, xenon; ${ }^{4} \mathrm{He}$, helium-4; ${ }^{20} \mathrm{Ne}$, neon-20; ${ }^{40} \mathrm{Ar}$, argon-40; ${ }^{84} \mathrm{Kr}$, krypton-84; ${ }^{132} \mathrm{Xe}$, xenon- $132 ;{ }^{22} \mathrm{Ne}$, neon-22; ${ }^{21} \mathrm{Ne}$, neon-21; ${ }^{36} \mathrm{Ar}$, argon-36; ${ }^{38} \mathrm{Ar}$, argon-38; ${ }^{86} \mathrm{Kr}$, krypton-86; ${ }^{130} \mathrm{Xe}$, xenon-130; $\mathrm{cm}^{3} / \mathrm{cm}^{3}$, cubic centimeter per cubic centimeter, molar ratio; *, values listed in Porcelli and others (2002); RAS, Riverside Air Standard; nr, not run; \%, percent; \pm , plus or minus]

\begin{tabular}{|c|c|c|c|c|c|c|c|c|c|c|c|c|c|}
\hline Sample & $\begin{array}{c}\mathrm{N}_{2} \\
\mathrm{~cm}^{3} / \mathbf{c m}^{3}\end{array}$ & $\begin{array}{c}\mathbf{O}_{2} \\
\mathbf{c m}^{3} / \mathbf{c m}^{3}\end{array}$ & & $\begin{array}{c}\mathrm{He} \\
\mathbf{c m}^{3} / \mathbf{c m}^{3}\end{array}$ & $\begin{array}{c}\mathrm{Ne} \\
\mathrm{cm}^{3} / \mathbf{c m}^{3}\end{array}$ & $\begin{array}{c}\mathrm{Ar} \\
\mathrm{cm}^{3} / \mathbf{c m}^{3}\end{array}$ & $\begin{array}{c}\mathrm{Kr} \\
\mathrm{cm}^{3} / \mathbf{c m}^{3}\end{array}$ & $\begin{array}{c}\mathrm{Xe} \\
\mathrm{cm}^{3} / \mathrm{cm}^{3}\end{array}$ & $\begin{array}{c}{ }^{4} \mathrm{He} \\
\mathrm{cm}^{3} / \mathbf{c m}^{3}\end{array}$ & $\begin{array}{c}{ }^{20} \mathrm{Ne} \\
\mathrm{cm}^{3} / \mathrm{cm}^{3}\end{array}$ & $\begin{array}{c}{ }^{40} \mathrm{Ar} \\
\mathrm{cm}^{3} / \mathbf{c m}^{3}\end{array}$ & $\begin{array}{c}{ }^{84} \mathbf{K r} \\
\mathbf{c m}^{3} / \mathrm{cm}^{3}\end{array}$ & $\begin{array}{c}\mathrm{cm}^{132} \mathrm{Xe} \\
\mathrm{cm}^{3} / \mathrm{cm}^{3}\end{array}$ \\
\hline Green Mountain $n=5,2014$ & $7.808 \mathrm{E}-1$ & $2.074 \mathrm{E}-1$ & & & & & & & $5.241 \mathrm{E}-6$ & $1.646 \mathrm{E}-5$ & $9.307 \mathrm{E}-3$ & $6.494 \mathrm{E}-4$ & $2.343 \mathrm{E}-5$ \\
\hline 1-sigma deviation & $4.2 \mathrm{E}-3$ & $4.5 \mathrm{E}-3$ & & & & & & & $1.8 \mathrm{E}-8$ & $1.7 \mathrm{E}-7$ & $3.6 \mathrm{E}-5$ & $1.8 \mathrm{E}-5$ & $7.1 \mathrm{E}-7$ \\
\hline Percent deviation & $0.5 \%$ & $2.2 \%$ & & & & & & & $0.3 \%$ & $1.0 \%$ & $0.4 \%$ & $2.7 \%$ & $3.0 \%$ \\
\hline Loveland average $n=6,2007$ & $7.783 \mathrm{E}-1$ & 2.104E-1 & & $5.240 \mathrm{E}-6$ & $1.818 \mathrm{E}-5$ & $9.341 \mathrm{E}-3$ & $1.140 \mathrm{E}-6$ & $8.700 \mathrm{E}-8$ & & & & & \\
\hline 1-sigma deviation & $8.4 \mathrm{E}-4$ & $9.5 \mathrm{E}-4$ & & $1.2 \mathrm{E}-8$ & $1.8 \mathrm{E}-7$ & $8.1 \mathrm{E}-5$ & $9.1 \mathrm{E}-9$ & $1.8 \mathrm{E}-9$ & & & & & \\
\hline Percent deviation & $0.1 \%$ & $0.4 \%$ & & $0.2 \%$ & $1.0 \%$ & $0.9 \%$ & $0.8 \%$ & $2.0 \%$ & & & & & \\
\hline $\begin{array}{l}\text { USGS Reston Groundwater Age } \\
\text { Dating Laboratory air } n=2\end{array}$ & 7.774E-1 & $2.110 \mathrm{E}-1$ & & $9.576 \mathrm{E}-6$ & $1.805 \mathrm{E}-5$ & $9.430 \mathrm{E}-3$ & $1.153 \mathrm{E}-6$ & $8.918 \mathrm{E}-8$ & & & & & \\
\hline 1-sigma deviation & $3.1 \mathrm{E}-4$ & $2.3 \mathrm{E}-4$ & & $3.6 \mathrm{E}-7$ & $1.9 \mathrm{E}-8$ & $8.5 \mathrm{E}-6$ & $6.0 \mathrm{E}-9$ & $3.2 \mathrm{E}-9$ & & & & & \\
\hline Percent deviation & $0.04 \%$ & $0.11 \%$ & & $3.80 \%$ & $0.10 \%$ & $0.09 \%$ & $0.52 \%$ & $3.58 \%$ & & & & & \\
\hline RAS standard $n=10$ & $7.808 \mathrm{E}-1$ & $2.095 \mathrm{E}-1$ & & $5.240 \mathrm{E}-6$ & $1.818 \mathrm{E}-5$ & $9.340 \mathrm{E}-3$ & $1.140 \mathrm{E}-6$ & $8.700 \mathrm{E}-8$ & $5.240 \mathrm{E}-6$ & $1.645 \mathrm{E}-5$ & $9.308 \mathrm{E}-3$ & $6.498 \mathrm{E}-4$ & 2.339E-5 \\
\hline 1-sigma deviation & $9.1 \mathrm{E}-4$ & $9.2 \mathrm{E}-4$ & & $3.0 \mathrm{E}-8$ & $1.7 \mathrm{E}-7$ & $3.4 \mathrm{E}-5$ & $1.4 \mathrm{E}-8$ & $2.5 \mathrm{E}-9$ & $5.0 \mathrm{E}-8$ & 4.0E-9 & $1.0 \mathrm{E}-5$ & $1.0 \mathrm{E}-5$ & $1.0 \mathrm{E}-6$ \\
\hline Percent deviation & $0.1 \%$ & $0.4 \%$ & & $0.6 \%$ & $1.0 \%$ & $0.4 \%$ & $1.2 \%$ & $2.9 \%$ & $1.0 \%$ & $0.02 \%$ & $0.1 \%$ & $1.5 \%$ & $4.3 \%$ \\
\hline Atmosphere* & $7.81 \mathrm{E}-2$ & $2.09 \mathrm{E}-2$ & & $5.240 \mathrm{E}-6$ & $1.818 \mathrm{E}-5$ & $9.340 \mathrm{E}-3$ & $1.140 \mathrm{E}-6$ & $8.700 \mathrm{E}-8$ & $5.240 \mathrm{E}-6$ & $1.645 \mathrm{E}-5$ & $9.309 \mathrm{E}-3$ & $6.498 \mathrm{E}-7$ & $2.339 \mathrm{E}-8$ \\
\hline Reported variation $( \pm)$ & & & & $5.0 \mathrm{E}-8$ & $4.0 \mathrm{E}-8$ & $1.0 \mathrm{E}-5$ & $1.0 \mathrm{E}-8$ & 1.0E-9 & $5.0 \mathrm{E}-8$ & $4.0 \mathrm{E}-8$ & $1.0 \mathrm{E}-5$ & $5.7 \mathrm{E}-9$ & $2.7 \mathrm{E}-10$ \\
\hline Percent variation & & & & $1.0 \%$ & $0.2 \%$ & $0.1 \%$ & $0.9 \%$ & $1.1 \%$ & $1.0 \%$ & $0.2 \%$ & $0.1 \%$ & $0.9 \%$ & $1.1 \%$ \\
\hline \multirow{2}{*}{ Sample } & $\mathbf{R}$ & ${ }^{20} \mathrm{Ne}$ & ${ }^{21} \mathrm{Ne}$ & ${ }^{40} \mathrm{Ar}$ & ${ }^{38} \mathrm{Ar}$ & ${ }^{86} \mathrm{Kr}$ & ${ }^{130} \mathrm{Xe}$ & & & & & & \\
\hline & $\overline{\mathbf{R}_{\mathrm{A}}}$ & $\overline{{ }^{22} \mathrm{Ne}}$ & $\overline{{ }^{22} \mathrm{Ne}}$ & $\overline{{ }^{36} \mathrm{Ar}}$ & $\overline{{ }^{36} \mathrm{Ar}}$ & $\overline{{ }^{84} \mathrm{Kr}}$ & $\overline{{ }^{132} \mathbf{X e}}$ & & & & & & \\
\hline Green Mountain n=5, 2014 & 0.999 & 9.795 & 0.029 & 295.6 & $\mathrm{nr}$ & 0.313 & 0.147 & & & & & & \\
\hline 1 sigma deviation & 0.005 & 0.006 & 0.000 & 0.5 & $\mathrm{nr}$ & 0.006 & 0.005 & & & & & & \\
\hline Percent deviation & $0.5 \%$ & $0.1 \%$ & $0.6 \%$ & $0.2 \%$ & $\mathrm{nr}$ & $1.9 \%$ & $3.2 \%$ & & & & & & \\
\hline Loveland average $n=6,2007$ & 0.998 & 9.805 & 0.029 & 297.4 & 0.191 & 0.304 & 0.149 & & & & & & \\
\hline 1-sigma deviation & 0.011 & 0.007 & 0.000 & 2.0 & 0.002 & 0.005 & 0.002 & & & & & & \\
\hline Percent deviation & $1.1 \%$ & $0.1 \%$ & $1.5 \%$ & $0.7 \%$ & $1.1 \%$ & $1.8 \%$ & $1.5 \%$ & & & & & & \\
\hline $\begin{array}{l}\text { USGS Reston Groundwater Age } \\
\text { Dating Laboratory air } n=2\end{array}$ & 0.637 & 9.800 & 0.029 & 296.3 & 0.190 & 0.304 & 0.149 & & & & & & \\
\hline 1-sigma deviation & 0.018 & 0.004 & 0.000 & 0.598 & 0.000 & 0.002 & 0.005 & & & & & & \\
\hline Percent deviation & $2.9 \%$ & $0.04 \%$ & $0.02 \%$ & $0.2 \%$ & $0.2 \%$ & $0.7 \%$ & $3.1 \%$ & & & & & & \\
\hline RAS standard $\mathrm{n}=10$ & 1.000 & 9.800 & 0.029 & 295.5 & 0.188 & 0.305 & 0.151 & & & & & & \\
\hline 1-sigma deviation & 0.010 & 0.008 & 0.000 & 2.4 & 0.002 & 0.002 & 0.005 & & & & & & \\
\hline Percent deviation & $1.0 \%$ & $0.1 \%$ & $0.6 \%$ & $0.8 \%$ & $1.1 \%$ & $0.8 \%$ & $3.4 \%$ & & & & & & \\
\hline Atmosphere* & 1.000 & 9.800 & 0.029 & 295.5 & 0.188 & 0.305 & 0.151 & & & & & & \\
\hline Reported variation $( \pm)$ & 0.013 & 0.08 & 0.000 & 0.5 & 0.000 & 0.003 & 0.002 & & & & & & \\
\hline Percent variation & $1.3 \%$ & $0.8 \%$ & $1.0 \%$ & $0.2 \%$ & $0.2 \%$ & $0.8 \%$ & $1.3 \%$ & & & & & & \\
\hline
\end{tabular}


of accepted values for the atmosphere and are a confirmation that the composition of the RAS is still within calibration limits (table 3). This simple process of verification is run approximately once a year to confirm the composition of the RAS. When the measured air compositions are not correct, a second air sample may be sampled and analyzed to confirm the off calibration of the RAS, and a decision can be made to remove the current running standard and reload the RAS from the laboratory's main cylinder of RAS gas.

\section{Generation of In-House Synthetic Air Equilibrated Water}

Though the verification of the RAS by running air samples is sufficient to refine the calibration of the instrument, the actual process of verifying the procedure practices is more complicated. The extraction process has many variables that could lead to less-than-ideal conditions to get accurate and complete extraction of dissolved gas from a sample. Beyerle and others (2000) proposed using laboratory-generated air equilibrated water (AEW) to calibrate techniques used. This process is also used in various other laboratories and a simple verification of technique (for example, USGS Reston Groundwater Age Dating
Laboratory and Lamont-Doherty Earth Observatory Noble Gas Laboratory), but the method varies greatly on just how a synthetic AEW sample is generated. In most cases, a large volume of water is left in a controlled-temperature room, which allows the mass of water to equilibrate with the atmosphere. Variables such as atmospheric pressure, and in some cases, air composition can vary over the period it takes for the mass of water to equilibrate with the atmosphere. This creates greater uncertainty in the actual calculated composition of the AEW and raises possible issues with the AEW's use as a QA and QC tool.

The USGS NGL has modified typical AEW techniques to create a process that will equilibrate a large volume of water $(\approx 20$ liters $)$ with air in less than 1.5 hours by using a commercially available gas-exchange membrane to exchange air rapidly in the water and using gas measurement probes (total dissolved gas pressure [TDGP]) and dissolved oxygen [DO]) to monitor the progression of the air exchange with the water. This minimizes the parameters that affect the equilibration process (temperature, air composition, and time), creating a QA and QC standard that is uniform and reproducible. The conceptual equilibrator is presented in figure 5. A stirred, glass reservoir of 20 liters of water is circulated by a 2 liters per minute metering pump through the exchange membrane, which is being fed a fresh supply of air by a diaphragm pump,

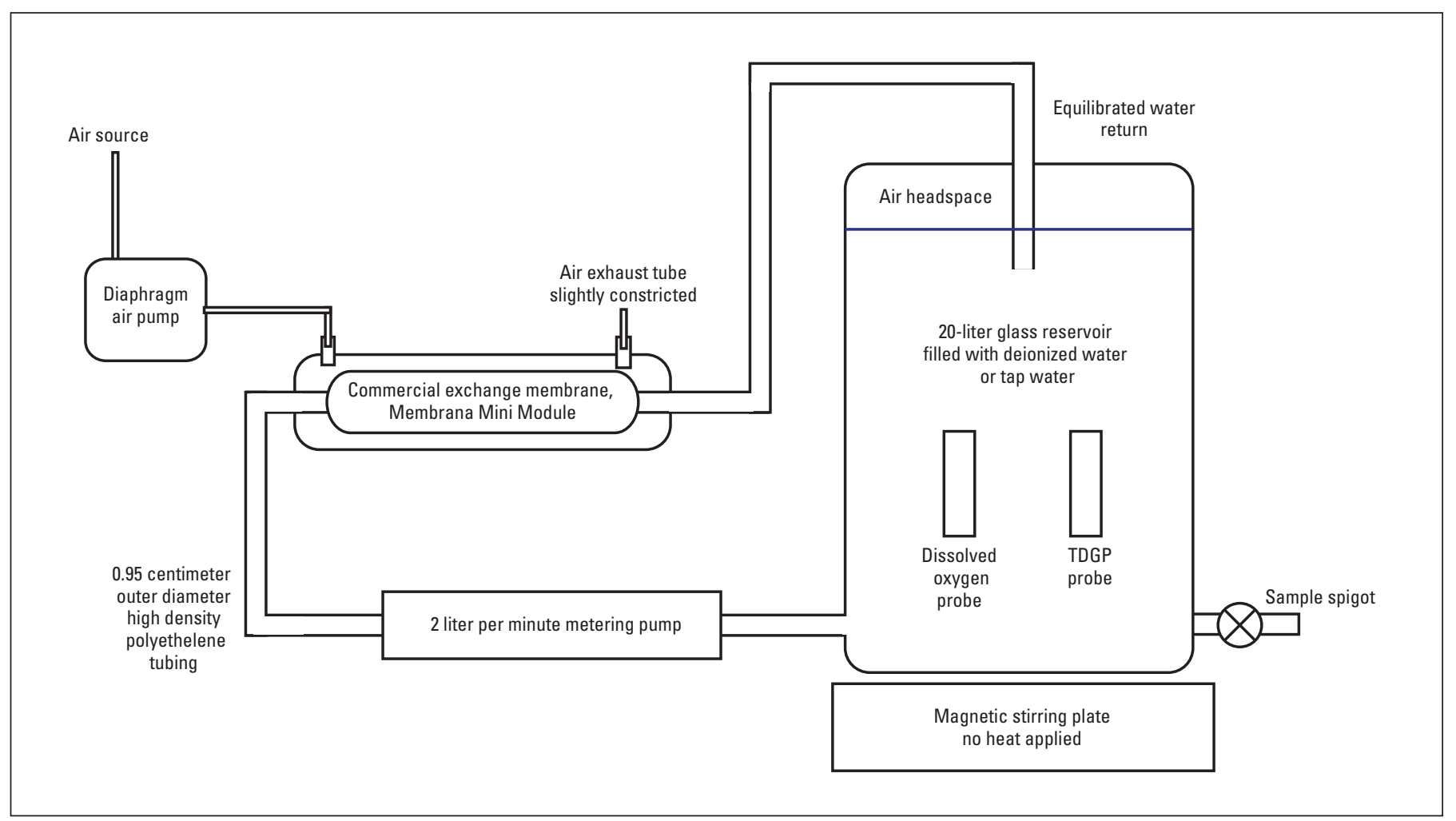

Figure 5. Conceptual representation of the equilibration apparatus for creating airequilibrated water. The commercial exchange membrane is Membrana Mini Module (G541) connected in line with the circulation loop system to the main reservoir. Total dissolved gas probe is a Point Four Systems P4 Tracker probe coupled with a Yellow Springs Instrument Pro ODO (optical dissolved oxygen meter), and they are fully submerged in the main reservoir to monitor total dissolved gas pressure and dissolved oxygen levels during the equilibration cycle. TDGP, total dissolved gas pressure. 
with a minor constriction on the air side of the membrane that increases the pressure above ambient as recommended by the manufacture. The TDGP and DO probes monitor the rate of equilibration (dissolved gas pressure and temperature with time) of the reservoir. AEW samples are prepared in a building free of extraneous sources of noble gases (Denver Federal Center, Lakewood, Colo., building 15). After stabilization of TDGP, DO, and temperature, copper sample tubes are filled through a bottom feed spigot in the reservoir and clamped according to field collection procedures recommended by the USGS NGL for sampling of noble gases.

Data are presented in figure $6 A$ and $6 B$ from two separate equilibration runs for the TDGP and DO meters from an experiment with deionized water and tap water as media. Deionized water was taken directly from an in-house source and filled the reservoir at room temperature, whereas the tap water was filled from the cold water spigot in the laboratory. Both experiments show that the amount of dissolved gas coming from a water system in the laboratory is over pressurized with respect to dissolved gas composition. With circulation through the exchange membrane, the air and water both arrive at an equilibrium level that is mainly dependent on the air pressure inside on the exchange membrane; external air pressure was measured at approximately 620 torr in the laboratory. One large difference between experiments $A$ and $B$ is that the tap water was cooler than room temperature (temperature $\approx 22{ }^{\circ} \mathrm{C}$ ), and the fluid had to equilibrate with the atmosphere and equilibrate with the room temperature. This increased the equilibration time needed for the reservoir. Figure $6 C$ shows the same experiment with tap water that has been allowed to thermally equilibrate overnight. The initial TDGP and DO data in figure $6 C$ still exhibit excess gas (noted by the dissolved gas pressure levels measured by the TDGP probe) even after more than 12 hours of stagnate thermal and dissolved gas equilibration with the laboratory environment. The equilibration rate is rapid and more stable after 1 hour than the data from experiment $B$ and produces equilibrated water after $\approx 60$ minutes.

The data gathered during the equilibration of the water are used to calculate the dissolved gas composition of the synthetic AEW. Implementing Henry's Law to compute the dissolved concentration in the reservoir:

$$
\mathrm{C}_{\mathrm{i}}=\mathrm{P}_{\mathrm{i}} / \mathrm{k}_{\mathrm{i}}
$$

where

$$
\begin{gathered}
\mathrm{C}_{\mathrm{i}}=\begin{array}{c}
\text { Concentration of gas species } i \text { in water (for } \\
\quad \text { example, } \mathrm{He}, \mathrm{Ne}, \mathrm{Ar}, \mathrm{Kr} \text {, and } \mathrm{Xe} \text { ) }
\end{array} \\
\mathrm{P}_{\mathrm{i}}=\begin{array}{c}
\text { Partial pressure of gas species } i \text { in the air- } \\
\text { Function of molar fraction and pressure }
\end{array} \\
\mathrm{k}_{\mathrm{i}} \quad \begin{array}{l}
\text { Henry's Law constant_-Function of } \\
\text { temperature and salinity }
\end{array}
\end{gathered}
$$

Here, the $\mathrm{Ci}$ is based on the molar fraction of the gas in air (fixed) by the measured pressure from the TDGP probe and Henry's Law constant as computed by Weiss (1970, 1971), Weiss and Kyser (1978), Clever (1979), and Smith and Kennedy (1983), based on salinity and temperature of the fluid. Dissolved gas analysis of the AEW samples run is presented in table 4 . The natural equilibration results show good comparative results with the error propagated, calculated concentrations with minor enrichment in observed $\mathrm{He}$ and a lower R/Ra in the December 2010 experiment, possibly due to He added from venting $\mathrm{He}$ in the laboratory building. The membrane equilibration experiments are similar but have less uncertainty associated with the parameters used to calculate the AEW concentrations and more reliability in the generation of the AEW standards.

This method represents a work in progress for the preparation of AEW samples but has produced the best results so far for the equilibration of water samples, and it is being adopted by the USGS NGL as the method to generate multiple QA and QC standards for evaluating procedural continuity for the measurement of dissolved gases in water. As a working method, a synthetic AEW is run for every 10 unknown samples within the sample stream, and the data are reported with the sample set as the laboratory QA and QC.

\section{Reporting of Outside Interlaboratory Data Comparisons}

The USGS NGL has participated in interlaboratory sample comparisons and plans to continue this practice in the future. This is one of the few ways that laboratories with different methods, instruments, and sampling procedures can compare results. Interlaboratory investigations will be used as part of the laboratory's QA and QC program, but an emphasis will be placed on methods used in the comparative study and possible pitfalls that could arise in the study.

For example, the most recent method has been published in Visser and others 2014). Here, blind samplings of several select wells were sampled for a variety of groundwater dating methods to show the actual distribution of groundwater age. This method of comparison of laboratory data can be a problem in that the different techniques involved could produce artificial differences in the comparison. In this comparison, a natural system was sampled but questions arose as to how much variability was occurring during the sampling of the wells involved. The number of samples taken and amount of time between the first and last sample can lead to natural variation in the sample waters from the wells, in addition to the different techniques used to sample (the largest issue in noble gas analysis).

In general, the goal of the laboratory QA and QC program is to pursue the best possible practices to ensure accuracy in the measurement of dissolved gases in water samples. Use of in-house standards, cross calibration of the standards with known samples, running of synthetic waters of known compositions, and participation in interlaboratory calibration studies are the best possible practices. In terms of activities reporting, a yearly summary of the QA and QC program activities will report on the general operation, maintenance, and concerns noted about operation activities. 

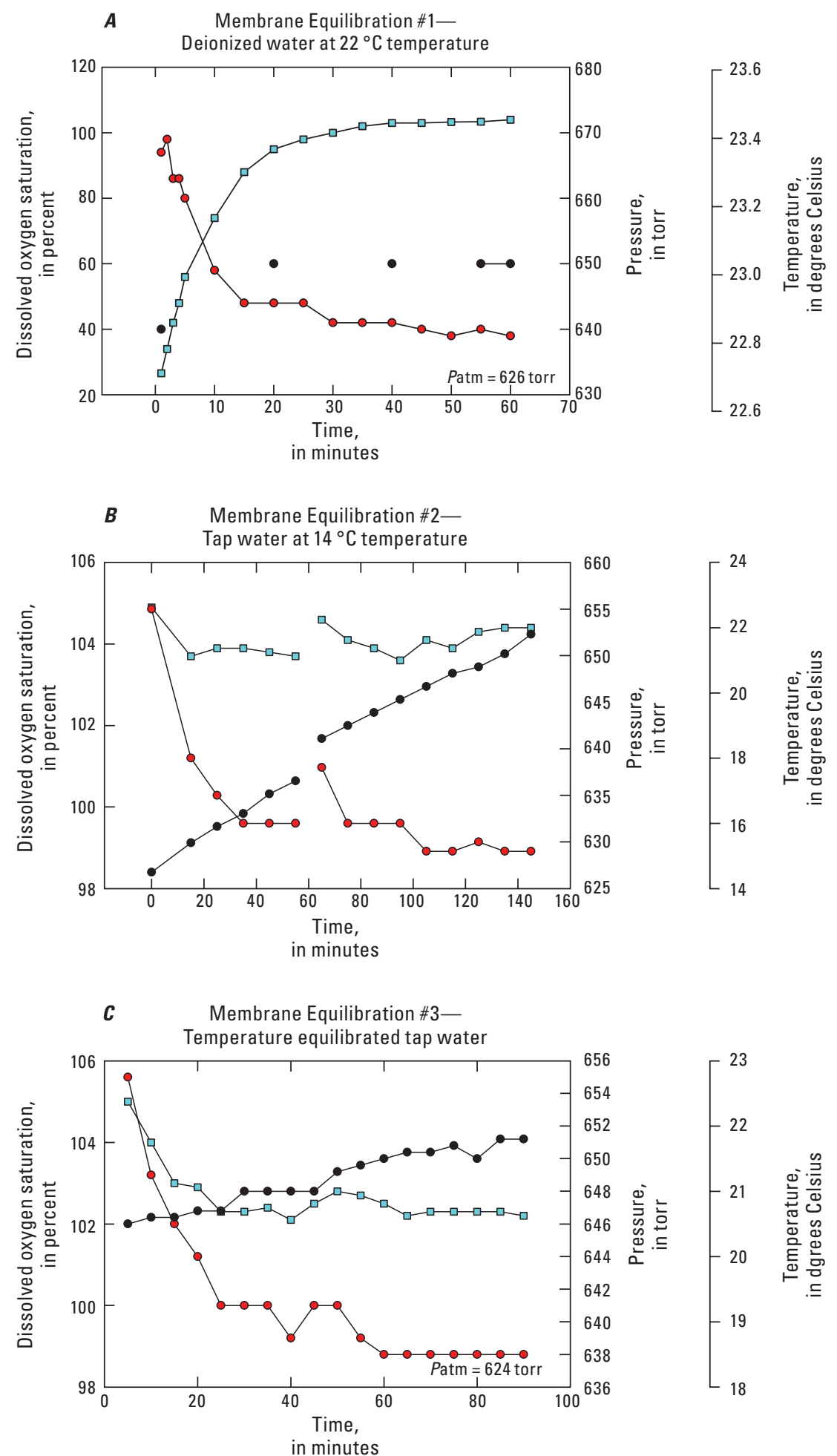

EXPLANATION

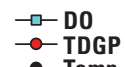

Figure 6. Plots of total dissolved gas pressure (TDGP), dissolved oxygen (D0), and temperature (Temp) against time for three separate air equilibrated water experiments. $A$, Experiment using deionized water at room temperature $\approx 22^{\circ} \mathrm{C}$; atmospheric pressure was 626 torr; $B$, Experiment using tap water at $14^{\circ} \mathrm{C}$ temperature; atmospheric pressure was 621 torr; $C$, experiment using temperature equilibrated tap water; atmospheric pressure was 624 torr. ${ }^{\circ} \mathrm{C}$, degrees Celsius; Patm, atmospheric pressure. 


\section{Table 4. Air equilibrated water summary.}

$\left[\mathrm{P}\right.$, Pressure in torr; T, temperature; ${ }^{\circ} \mathrm{C}$, degrees Celsius; AEW, air equilibrated water; DI, deionized water; $\mathrm{N}_{2}$, nitrogen; He, helium; Ne, neon; Ar, argon; Kr, krypton; Xe, xenon; ${ }^{20} \mathrm{Ne}$, neon-20; ${ }^{22} \mathrm{Ne}$, neon-22; ${ }^{40} \mathrm{Ar}$, argon-40; ${ }^{36} \mathrm{Ar}$, argon-36; ${ }^{86} \mathrm{Kr}$, krypton- $86 ;{ }^{84} \mathrm{Kr}$, krypton- $84 ;{ }^{130} \mathrm{Xe}$, xenon- $130 ;{ }^{132} \mathrm{Xe}$, xenon- $132 ; \mathrm{cm}^{3} \mathrm{STP} / \mathrm{g}_{\mathrm{H} 2 \mathrm{O}}$ cubic centimeter at standard temperature and pressure per gram of water; \pm , plus or minus; MM-YYYY, dates appear as month-year]

\begin{tabular}{|c|c|c|c|c|c|c|c|c|c|c|c|c|c|c|}
\hline Air equilibrated water & $\begin{array}{c}\text { Pressure } \\
\text { torr }\end{array}$ & $\begin{array}{c}\text { Temperature } \\
{ }^{\circ} \mathrm{C}\end{array}$ & & $\begin{array}{c}\mathbf{N}_{2} \\
\mathrm{~cm}^{3} \mathrm{STP} / \mathbf{g}_{(\mathrm{H} 20)} \\
\end{array}$ & $\begin{array}{c}\mathrm{He} \\
\mathrm{cm}^{3} \mathbf{S T P} / \mathbf{g}_{(\mathrm{H} 20)} \\
\end{array}$ & $\begin{array}{c}\mathrm{Ne} \\
\mathrm{cm}^{3} \mathrm{STP} / \mathbf{g}_{\text {(H20) }} \\
\end{array}$ & $\begin{array}{c}\mathrm{Ar} \\
\mathrm{cm}^{3} \mathrm{STP} / \mathbf{g}_{(\mathrm{H} 20)} \\
\end{array}$ & $\begin{array}{c}\mathrm{Kr} \\
\mathrm{cm}^{3} \mathrm{STP} / \mathbf{g}_{(\mathrm{H} 20)}\end{array}$ & $\begin{array}{c}\mathrm{Xe} \\
\mathrm{cm}^{3} \mathrm{STP} / \mathbf{g}_{(\mathrm{H} 20)} \\
\end{array}$ & $\frac{\mathbf{R}}{\mathbf{R}_{\mathrm{A}}}$ & $\frac{{ }^{20} \mathrm{Ne}}{{ }^{22} \mathrm{Ne}}$ & $\frac{{ }^{40} \mathrm{Ar}}{{ }^{36} \mathrm{Ar}}$ & $\frac{{ }^{86} \mathrm{Kr}}{{ }^{84} \mathrm{Kr}}$ & $\frac{{ }^{130} \mathbf{X e}}{{ }^{132} \mathbf{X e}}$ \\
\hline $\begin{array}{l}\text { AEW 12-2010 } \\
\mathrm{n}=6 \\
\text { Natural equilibration }\end{array}$ & $\begin{array}{l}620 \\
\pm 12\end{array}$ & $\begin{array}{l}20.8 \\
\pm 2\end{array}$ & $\begin{array}{l}\text { Measured } \\
\text { 1-sigma deviation }\end{array}$ & $\begin{array}{l}9.614 \mathrm{E}-3 \\
5.2 \mathrm{E}-5\end{array}$ & $\begin{array}{l}3.791 \mathrm{E}-8 \\
1.1 \mathrm{E}-11\end{array}$ & $\begin{array}{l}1.516 \mathrm{E}-7 \\
1.1 \mathrm{E}-11\end{array}$ & $\begin{array}{l}2.498 \mathrm{E}-4 \\
2.6 \mathrm{E}-5\end{array}$ & $\begin{array}{l}5.386 \mathrm{E}-8 \\
2.2 \mathrm{E}-11\end{array}$ & $\begin{array}{l}7.405 \mathrm{E}-9 \\
2.5 \mathrm{E}-11\end{array}$ & $\begin{array}{l}1.047 \\
0.009\end{array}$ & $\begin{array}{l}9.810 \\
0.001\end{array}$ & $\begin{array}{r}296.8 \\
0.5\end{array}$ & $\begin{array}{l}0.304 \\
0.005\end{array}$ & $\begin{array}{l}0.152 \\
0.017\end{array}$ \\
\hline DI water & & & $\begin{array}{l}\text { Calculated } \\
\pm\end{array}$ & $\begin{array}{l}9.282 \mathrm{E}-3 \\
3.6 \mathrm{E}-4\end{array}$ & $\begin{array}{l}3.618 \mathrm{E}-8 \\
6.5 \mathrm{E}-10\end{array}$ & $\begin{array}{l}1.478 \mathrm{E}-7 \\
3.4 \mathrm{E}-9\end{array}$ & $\begin{array}{l}2.418 \mathrm{E}-4 \\
1.0 \mathrm{E}-5\end{array}$ & $\begin{array}{l}5.332 \mathrm{E}-8 \\
2.7 \mathrm{E}-9\end{array}$ & $\begin{array}{l}\text { 7.189E-9 } \\
4.4 \mathrm{E}-10\end{array}$ & $\begin{array}{l}0.983 \\
0.010\end{array}$ & $\begin{array}{l}9.800 \\
0.080\end{array}$ & $\begin{array}{r}295.5 \\
0.5\end{array}$ & $\begin{array}{l}0.305 \\
0.000\end{array}$ & $\begin{array}{l}0.151 \\
0.000\end{array}$ \\
\hline $\begin{array}{l}\text { AEW 12-2011 } \\
\mathrm{n}=8 \\
\text { Natural equilibration }\end{array}$ & $\begin{array}{l}624 \\
\pm 12\end{array}$ & $\begin{array}{l}21 \\
\pm 2\end{array}$ & $\begin{array}{l}\text { Measured } \\
\text { 1-sigma deviation }\end{array}$ & $\begin{array}{l}9.746 \mathrm{E}-3 \\
1.8 \mathrm{E}-5\end{array}$ & $\begin{array}{l}3.647 \mathrm{E}-8 \\
2.3 \mathrm{E}-12\end{array}$ & $\begin{array}{l}1.499 \mathrm{E}-7 \\
7.2 \mathrm{E}-12\end{array}$ & $\begin{array}{l}2.481 \mathrm{E}-4 \\
1.5 \mathrm{E}-5\end{array}$ & $\begin{array}{l}5.532 \mathrm{E}-8 \\
2.1 \mathrm{E}-11\end{array}$ & $\begin{array}{l}7.547 \mathrm{E}-9 \\
1.3 \mathrm{E}-11\end{array}$ & $\begin{array}{l}0.993 \\
0.008\end{array}$ & $\begin{array}{l}9.805 \\
0.001\end{array}$ & $\begin{array}{r}294.5 \\
0.5\end{array}$ & $\begin{array}{l}0.297 \\
0.002\end{array}$ & $\begin{array}{l}0.152 \\
0.011\end{array}$ \\
\hline DI water & & & $\begin{array}{l}\text { Calculated } \\
\pm\end{array}$ & $\begin{array}{l}9.505 \mathrm{E}-3 \\
3.4 \mathrm{E}-4\end{array}$ & $\begin{array}{l}3.621 \mathrm{E}-8 \\
7.7 \mathrm{E}-10\end{array}$ & $\begin{array}{l}1.490 \mathrm{E}-7 \\
3.6 \mathrm{E}-9\end{array}$ & $\begin{array}{l}2.483 \mathrm{E}-4 \\
9.5 \mathrm{E}-6\end{array}$ & $\begin{array}{l}5.519 \mathrm{E}-8 \\
2.5 \mathrm{E}-9\end{array}$ & $\begin{array}{l}7.502 \mathrm{E}-9 \\
4.0 \mathrm{E}-10\end{array}$ & $\begin{array}{l}0.983 \\
0.010\end{array}$ & $\begin{array}{l}9.800 \\
0.080\end{array}$ & $\begin{array}{r}295.5 \\
0.5\end{array}$ & $\begin{array}{l}0.305 \\
0.000\end{array}$ & $\begin{array}{l}0.151 \\
0.000\end{array}$ \\
\hline $\begin{array}{l}\text { AEW 6-2013 } \\
\mathrm{n}=3 \\
\text { Membrane equilibration }\end{array}$ & $\begin{array}{r}640 \\
\pm 5\end{array}$ & $\begin{array}{l}23 \\
\pm 0.5\end{array}$ & $\begin{array}{l}\text { Measured } \\
1 \text {-sigma deviation }\end{array}$ & $\begin{array}{l}9.597 \mathrm{E}-3 \\
5.7 \mathrm{E}-4\end{array}$ & $\begin{array}{l}3.750 \mathrm{E}-8 \\
3.1 \mathrm{E}-10\end{array}$ & $\begin{array}{l}1.507 \mathrm{E}-7 \\
1.2 \mathrm{E}-9\end{array}$ & $\begin{array}{l}2.392 \mathrm{E}-4 \\
5.5 \mathrm{E}-7\end{array}$ & $\begin{array}{l}5.269 \mathrm{E}-8 \\
7.4 \mathrm{E}-11\end{array}$ & $\begin{array}{l}\text { 7.295E-9 } \\
8.8 \mathrm{E}-11\end{array}$ & $\begin{array}{l}0.987 \\
0.011\end{array}$ & $\begin{array}{l}9.801 \\
0.007\end{array}$ & $\begin{array}{r}296.0 \\
0.8\end{array}$ & $\begin{array}{l}0.304 \\
0.001\end{array}$ & $\begin{array}{l}0.152 \\
0.003\end{array}$ \\
\hline DI water & & & $\begin{array}{l}\text { Calculated } \\
\pm\end{array}$ & $\begin{array}{l}9.475 \mathrm{E}-3 \\
1.0 \mathrm{E}-4\end{array}$ & $\begin{array}{l}3.717 \mathrm{E}-8 \\
2.5 \mathrm{E}-10\end{array}$ & $\begin{array}{l}1.516 \mathrm{E}-7 \\
1.2 \mathrm{E}-9\end{array}$ & $\begin{array}{l}2.467 \mathrm{E}-4 \\
2.9 \mathrm{E}-6\end{array}$ & $\begin{array}{l}5.425 \mathrm{E}-8 \\
7.5 \mathrm{E}-10\end{array}$ & $\begin{array}{l}7.295 \mathrm{E}-9 \\
1.2 \mathrm{E}-10\end{array}$ & $\begin{array}{l}0.983 \\
0.010\end{array}$ & $\begin{array}{l}9.800 \\
0.080\end{array}$ & $\begin{array}{r}295.5 \\
0.5\end{array}$ & $\begin{array}{l}0.305 \\
0.000\end{array}$ & $\begin{array}{l}0.151 \\
0.000\end{array}$ \\
\hline $\begin{array}{l}\text { AEW 9-2013 } \\
n=5\end{array}$ & $\begin{array}{r}630 \\
\pm 5\end{array}$ & $\begin{array}{l}22 \\
\pm 1.0\end{array}$ & $\begin{array}{l}\text { Measured } \\
\text { 1-sigma deviation }\end{array}$ & $\begin{array}{l}1.000 \mathrm{E}-2 \\
5.0 \mathrm{E}-4\end{array}$ & $\begin{array}{l}3.736 \mathrm{E}-8 \\
3.9 \mathrm{E}-10\end{array}$ & $\begin{array}{l}1.507 \mathrm{E}-7 \\
1.8 \mathrm{E}-9\end{array}$ & $\begin{array}{l}2.476 \mathrm{E}-4 \\
2.8 \mathrm{E}-6\end{array}$ & $\begin{array}{l}5.482 \mathrm{E}-8 \\
9.8 \mathrm{E}-10\end{array}$ & $\begin{array}{l}7.401 \mathrm{E}-9 \\
1.8 \mathrm{E}-10\end{array}$ & $\begin{array}{l}0.992 \\
0.013\end{array}$ & $\begin{array}{l}9.825 \\
0.011\end{array}$ & $\begin{array}{r}295.9 \\
0.5\end{array}$ & $\begin{array}{l}0.303 \\
0.001\end{array}$ & $\begin{array}{l}0.150 \\
0.002\end{array}$ \\
\hline & & & $\begin{array}{l}\text { Calculated } \\
\pm\end{array}$ & $\begin{array}{l}9.488 \mathrm{E}-3 \\
2.0 \mathrm{E}-4\end{array}$ & $\begin{array}{l}3.668 \mathrm{E}-8 \\
3.0 \mathrm{E}-10\end{array}$ & $\begin{array}{l}1.503 \mathrm{E}-7 \\
1.7 \mathrm{E}-9\end{array}$ & $\begin{array}{l}2.475 \mathrm{E}-4 \\
5.6 \mathrm{E}-6\end{array}$ & $\begin{array}{l}5.471 \mathrm{E}-8 \\
1.5 \mathrm{E}-9\end{array}$ & $\begin{array}{l}7.396 \mathrm{E}-9 \\
2.5 \mathrm{E}-10\end{array}$ & $\begin{array}{l}0.983 \\
0.010\end{array}$ & $\begin{array}{l}9.800 \\
0.080\end{array}$ & $\begin{array}{r}295.5 \\
0.5 \\
\end{array}$ & $\begin{array}{l}0.305 \\
0.000\end{array}$ & $\begin{array}{l}0.151 \\
0.000 \\
\end{array}$ \\
\hline
\end{tabular}




\section{Summary}

The standard operating procedures for the measurement of dissolved gases in water samples follow a straightforward progression of extraction on an ultralow vacuum extraction line, purification, cryogenic separation of components and subsequent measurement of individual components on Residual Gas Analyzer Model 200 and Mass Analyzer Products Model 215-50 mass spectrometers. The raw data are compiled and processed by the application of calibration curves generated from an analysis of a calibrated in-house standard. A quality control and quality assurance program outlines the procedures for the verification of the composition on the in-house standard used and a method for the generation of artificial, dissolved gas standards under controlled conditions.

The artificially generated standards are managed like the unknown samples and provide a secondary confirmation of not only the operation of the mass spectrometers but also a crosscheck of the procedures used for the extraction of the dissolved gas fraction from water matrix. This use of artificial standards is complemented by the participation in interlaboratory crosscalibration studies to ensure accuracy of data produced from the laboratory.

\section{References Cited}

Aeschbach-Hertig, Werner, Peeters, Frank, Beyerle, Uus, and Kipfer, Rolf, 1999, Interpretation of dissolved atmospheric noble gases in natural waters: Water Resource Research, v. 35 , no. 9 , p. 2779-2792.

Aeschbach-Hertig, Werner, Peeters, Frank, Beyerle, Uus, and Kipfer, Rolf, 2000, Palaeotemperature reconstruction from noble gases in ground taking into account equilibration with entrapped air:" Nature, v. 405, p. 1040-1044.

Ballentine, C.J., and Hall, C.M., 1999, Determining paleotemperature and other variables by using an error-weighted, nonlinear inversion of noble gas concentrations in water: Geochimica et Cosmochimica Acta, v. 63, no. 16, p. 2315-2336.

Bayer, Reinhold, Schlosser, Peter, Bonisch, Gerhard, Rupp, Hans, Zaucker, Fritz, and Zimmek, Gerhard, 1989, Performance and blank components of a mass spectrometric system for routine measurement of helium isotopes and tritium by the ${ }^{3} \mathrm{He}$ ingrowth method: Heidelberg, Germany, Springer-Verlag, p. 241-279.

Beyerle, Urs, Aeschbach-Hertig, Werner, Imboden, D.M., Baur, Heinrich, Graf, Thomas, Kipfer, Rolf, 2000, A mass spectrometric system for the analysis of noble gases and tritium from water samples: Environmental Science and Technology, v. 34, no 10, p. 2042-2050.
Christenson, Scott, Hunt, A.G., and Parkhurst, D.L., 2009, Geochemical investigation of the Arbuckle-Simpson aquifer, south-central Oklahoma, 2004-06: U.S. Geological Survey Scientific Investigations Report 2009-5036, 50 p.

Clarke, W.B., Jenkins, W.J., and Top, Z., 1976, Determination of tritium by mass-spectrometric measurement of ${ }^{3} \mathrm{He}$ : The International Journal of Applied Radiation and isotopies, v. 27 , no. 9 , p. 515-522.

Clever, H.L., ed., 1979, Krypton, xenon and radon-Gas solubilities-Solubility data series, v. 2: New York, Pergamon Press, 360 p.

Heaton, T.H.E., and Vogel, J.C., 1981, "Excess Air" in Groundwater: Journal of Hydrology, v. 50, p. 201-216.

Hunt, A.G., Lambert, R.B., and Fahlquist, L., 2010, Sources of groundwater based on helium analyses in and near the freshwater/saline-water transition zone of the San Antonio segment of the Edwards aquifer, south-central Texas, 2002-03: U.S. Geological Survey Scientific Investigations Report 2010-5030, 15 p.

Katz, B.G., McBride, W.S., Hunt, A.G., Crandall, P.A., Metz, P.A., Eberts, S.M., and Berndt, M.P., 2009, Vulnerability of a public supply well in a karstic aquifer to contamination: Groundwater, v. 47, no. 3, p. 438-452.

Kulongoski, J.T., and Hilton, D.R., 2002, A quadrupolebased mass spectrometric system for the determination of noble gas abundances in fluids: Geochemistry Geophysics Geosystems, v. 3, no. 6, 10 p. [Also available at http://dx.doi.org/10.1029/201GC000267.]

Lambert, R.B., Hunt, A.G., Stanton, G.P., and Nyman, M.B., 2009, Water-level, borehole geophysical log, and waterquality data from wells transecting the freshwater/salinewater interface of the San Antonio segment of the Edwards aquifer, south-central Texas, 1999-2007: U.S. Geological Survey Data Series 403 [variously paged]. [Also available at http://pubs.usgs.gov/ds/403/.]

McMahon, P.B., Thomas, J.C., and Hunt, A.G., 2013, Groundwater ages and mixing in the Piceance Basin natural gas province, Colorado: Environmental Science Technology, 2013, v. 47, no 23, p. 13250-13257.

McMahon, P.B., Caldwell, R.R, Galloway, J.M., Valder, J.F., and Hunt, A.G., 2015, Quality and age of shallow groundwater in the Bakken Formation production area, Williston Basin, Montana and North Dakota: Groundwater, v. 53, no. S1, p. 81-94.

McNaught, A.D., and Wilkinson, A., comp., 1997, IUPAC compendium of chemical terminology (the "Gold Book") (2d ed.): Oxford, United Kingdom, Blackwell Scientific Publications, ISBN 0-9678550-9-8, 464 p. 
National Ocean and Atmospheric Administration (NOAA), 1976, U.S. Standard Atmosphere: Washington, D.C., U.S. Government Printing Office.

Naus, C.A., McCleskey, R.B., Nordstrom, D.K., Donohoe, L.C., Hunt, A.G., Paillet, F.L., Morin, R.H., and Verplanck, P.L., 2005, Questa baseline and pre-mining ground-water quality investigation. 5. well installation, water level data, and surface- and ground-water geochemistry in the Straight Creek drainage basin, Red River Valley, New Mexico, 2001-03: U.S. Geological Survey Scientific Investigations Report 2005-5088, 220 p.

Nordstrom, D.K., McCleskey, R.B., Hunt, A.G., and Naus, C.A., 2005, Questa baseline and pre-mining ground-water quality investigation. 14. interpretation of ground-water geochemistry in catchments other than the Straight Creek catchment, Red River valley, Taos County, New Mexico, 2002-2003: U.S. Geological Survey Scientific Investigations Report 2005-5050, 94 p.

Ozima, Minoru, and Podosek, F.A., 2001, Noble gas geochemistry, 2nd edition: United Kingdom, Cambridge University Press, Cambridge.

Plummer, L.N., Eggleston, J.R., Andreasen, D.C., Raffensperger, J.P., Hunt, A.G., and Casile, G.C., 2012, Old groundwater in parts of the upper Patapsco aquifer, Atlantic Coastal Plain, Maryland, USA - Evidence from radiocarbon, chlorine-36 and helium-4: Hydrogeology Journal, v. 20 , no. 7 , p. 1269-1294.

Plummer, L.N., Sibrell, P.L., Casile, G.C., Busenberg, E., Hunt, A.G., and Schlosser, P., 2013, Tracing groundwater with low-level detections of halogenated VOCs in a fractured carbonate-rock aquifer, Leetown Science Center, West Virginia, U.S.A.: Applied Geochemistry, v. 33, p. 260-280.

Porcelli, D.P., Ballentine, C.J., and Wieler, Rainer, 2002, An overview of noble gas geochemistry and cosmochemistry, chapter 2 of Porcelli, D.P., Ballentine, C.J., Wieler, Rainer, eds., Noble gases in geochemistry and cosmochemistry: Mineralogical Society of America, Reviews in Mineralogy and Geochemistry, v. 47, p. 1-19.

Poreda, R.J., Cerling, T.E., and Salomon, D.K., 1988, Tritium and helium isotopes as hydrologic tracers in a shallow unconfined aquifer: Journal of Hydrology, v. 103, nos. 1-2, p. 1-9.

Sanford, W.E., Doughten, M.W., Copland, T.B., Hunt, A.G., and Bullen, T.D., 2013, Evidence for high salinity of Early Cretaceous seawater from the Chesapeake Bay crater: Nature, v. 503, p. 252-256.
Schlosser, Peter, 1992, Tritium $/{ }^{\beta} \mathrm{He}$ dating of waters in natural systems, in Loosli, H.H., and Mazor, E., eds., Isotopes of noble gases as tracers in environmental studies-Proceedings of a consultants meeting on isotopes of noble gases as tracers in environmental studies, Vienna, Austria, May 29-June 2, 1989: Vienna, Austria, International Atomic Energy Agency, Panel Proceedings Series, p. 123-145.

Smith, S.P., and Kennedy B.M., 1983, The solubility of noble gases in NaCL brine: Geochimica et Cosmochimica Acta, v. 47 , no. 3, p. 503-515.

Solomon, D.K., Poreda, R.J., Schiff, S.L., and Cherry, J.A., 1992, Tritium and helium 3 as groundwater age tracers in the Borden aquifer: Water Resources Research, v. 28, no. 3, p. 741-755.

Solomon, D.K., Hunt, A.G., and Poreda, J., 1996, Source of radiogenic helium-4 in shallow aquifers-Implications for dating young groundwater: Water Resources Research, v. 32 , no. 6 , p. 1805-1813.

Stute, Martin, and Sonntag, C., 1992, Palaeotemperatures derived from noble gases dissolved in groundwater and in relation to soil temperature, in Loosli, H.H., and Mazor, E., - Isotopes of noble gases as tracers in environmental studies-Proceedings of a consultants meeting on isotopes of noble gases as tracers in environmental studies, Vienna, Austria, May 29-June 2, 1989: Vienna, Austria, International Atomic Energy Agency, Panel Proceedings Series, p. 111-122.

Visser, Ate, Fourré, E., Barbecot, Florent, Aquilina, Luc, Labasque, Thierry, Vernaud, Virginie, Esser, B.K., 2014, Intercomparison of tritium and noble gases analyses, ${ }^{3} \mathrm{H} /{ }^{3} \mathrm{He}$ ages and derived parameters excess air and recharge temperature: Applied Geochemistry, v. 50, p. 130-141.

Wallington, M.J., 1971, The focal properties of electron bombardment ion sources for mass spectrometers: Journal of Physics E: Scientific Instruments, v. 4, no. 1, p. 1-8.

Weiss, R.F., 1970, The solubility of nitrogen, oxygen, and argon in water and seawater Deep Sea Research and Oceanographic Abstracts, p. 721-735.

Weiss, R.F., 1971, Solubility of helium and neon in water and seawater: Journal of Chemical Engineering Data, v. 16, p. 235-241.

Weiss, R.F., and Kyser, T.K., 1978, Solubility of krypton in water and seawater: Journal of Chemical Engineering Data, v. 23, p. $69-72$. 
Publishing support provided by:

Denver Publishing Service Center, Denver, Colorado

For more information concerning this publication, contact:

Center Director, USGS Crustal Geophysics and Geochemistry Science Center Box 25046, MS 964

Denver, C0 80225

(303) 236-1312

Or visit the Crustal Geophysics and Geochemistry Science Center Web site at: http://crustal.usgs.gov/

This publication is available online at: http://dx.doi.org/10.3133/tm5A11 

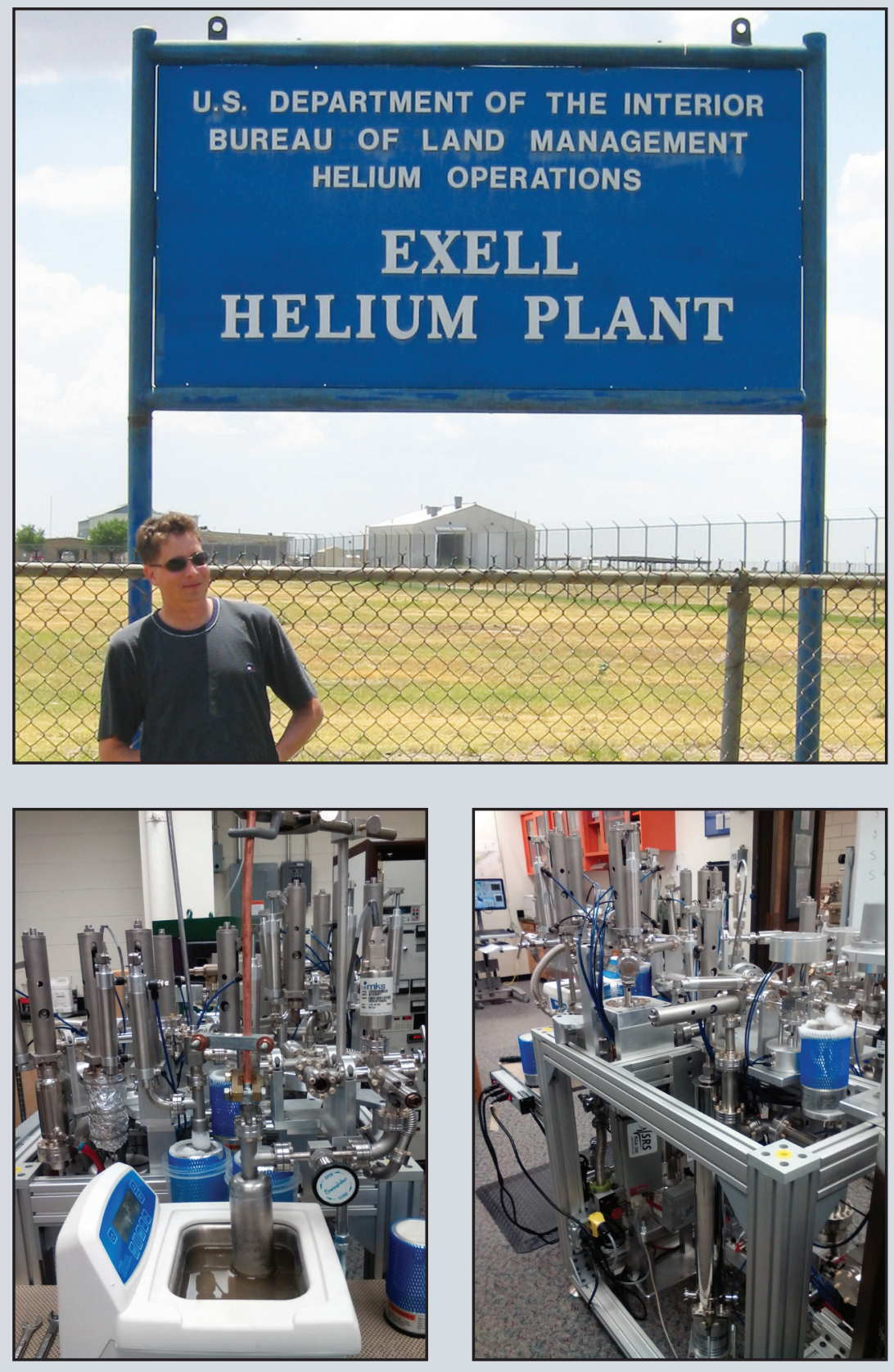